\title{
Die Fabrik wird salonfähig - der Erste Weltkrieg
}

Am 29. Juni 1914, einen Tag nach dem Attentat auf den österreichischen Thronfolger Erzherzog Franz Ferdinand (1863-1914) in Sarajevo, veröffentliche die russische Zeitschrift Iskry Zeichnungen und Fotografien des Anschlags und der Festnahme des Täters. ${ }^{1}$ In den folgenden Juliwochen war der sich anbahnende Konflikt in den Illustrierten präsent. Dies zeigen unter anderem Portraits ausländischer Politiker wie das des französischen Präsidenten Raymond Poincaré (1860-1934), der zu dieser Zeit das Zarenreich besuchte. ${ }^{2}$ Pferderennen, Erinnerungsveranstaltungen für die Schriftsteller Tolstoj und Čechov, Pogrome oder Brände dominierten jedoch die Berichterstattung nach wie vor. Dies änderte sich mit der Ausgabe der Iskry vom 27. Juli 1914. Vtoraja otečestvennaja vojna (Der zweite vaterländische Krieg) titelte die Zeitschrift und präsentierte ihren Lesern Fotografien der Teilmobilmachung der russischen Armee, ${ }^{3}$ Portraits russischer Generäle und militärischer Verbündeter ${ }^{4}$ sowie eine ganzseitige Aufnahme der englischen Flotte. ${ }^{5}$ Damit war der Erste Weltkrieg in den Illustrierten angekommen und erreichte die Leser in ihrem Alltagsleben. In den ersten Augustwochen prägten die Fotografien von russischen und verbündeten Militärs und Truppenverbänden die Zeitschriften. Bereits eine Woche nach Beginn des Kriegs erweiterte Iskry diese Motivauswahl um Aufnahmen ziviler Opfern des deutschen Vormarschs in Belgien. ${ }^{6}$ Die Fotografien in Illustrierten ergänzten die Vorstellungen vom Krieg, die sich die Leser nach Schilderungen von Angehörigen, Presseberichten und Gerüchten machten.

Als das Deutsche Reich am 1. August Russland den Krieg erklärte, war die Gesellschaft des Zarenreichs politisch und sozial zutiefst gespalten. Die politische Elite hoffte, der Konflikt werde die unterschiedlichen Lager einen

1 o. A.: Ubijstvo v Saraeve, in: Iskry, 29.06.1914, S. 194.

2 o. A.: Gost' Rossii, in: Iskry, 06.07.1914, S. 201; Priezd francusov, in: Iskry, 06.07.1914, S. 202.

3 o. A.: Mobilizacija russkoj armii, in: Iskry, 27.07.1914, S. 227. Das Zarenreich veranlasste die Mobilmachung seiner Truppen im Vergleich zu anderen Ländern relativ früh. Diesen Umstand instrumentalisierten deutsche Politiker, um einen Krieg insbesondere vor den Sozialisten zu rechtfertigen. Dominic Lieven: Towards the Flame. Empire, War and the End of Tsarist Russia, London 2015, S. 337-338.

4 o. A.: Boždi russkoj armii, in: Iskry, 27.07.1914, S. 226; o. A.: Naši sojuzniki, in: Iskry, 27.07.1914, S. 230.

5 o. A.: Anglijskij flot, in: Iskry, 27.07.1914, S. 232.

6 o. A.: Žertvy nemeckich zverstv, in: Iskry, 10.08.1914, S. 247.

(C) LENKA FEHRENBACH, 2020 | DOI:10.30965/9783657703081_010

This is an open access chapter distributed under the terms of the CC BY-NC-ND 4e licensenerenbach - 9783657703081 
und auf das gemeinsame Ziel, die Verteidigung des Vaterlands, ausrichten. ${ }^{7}$ In den großen Städten schien diese Hoffnung zunächst aufzugehen, ${ }^{8}$ und sowohl die konservative wie die liberale Presse folgte den Richtlinien einer patriotischen Berichterstattung. Auch der Zar war bemüht, seine Untertanen hinter sich zu scharen, und wandte sich gezielt an neue Teile der Bevölkerung wie die Fabrikarbeiter. ${ }^{9}$ Das vorliegende Kapitel beruht auf der Annahme, dass sich die neue politische Situation und deren Auswirkungen auf den Alltag der russischen Bevölkerung auch in den Bildwelten des Zarenreichs niederschlugen. Bernd Hüppauf stellt mit Blick auf den Ersten Weltkrieg die These auf, dass erst durch die Verwendung von Medien Gesellschaften in der Lage gewesen seien, sich den Krieg als Ganzes vorstellen und wahrnehmen zu können. ${ }^{10}$ Davon ausgehend wird im Folgenden untersucht, wie sich vor dem Hintergrund des Kriegs die Bedeutung der Industrie und ihre Darstellung in der russischen Öffentlichkeit wandelte. In zwei Teilen wird eruiert, welche Veränderungen das Motiv der Fabrik unter den Vorzeichen des Konflikts erfuhr und welche Rolle es im russischen Kriegsnarrativ einnahm. Zunächst geht die Analyse darauf ein, wie das Konsumprodukt illustrierte Zeitschrift zu Beginn und während des Kriegs über Fabriken berichtete. Es wird skizziert, inwiefern die neuen politischen Rahmenbedingungen die Darstellungen von Industrie veränderten und wie sich innerhalb des Mediums die Haltung gegenüber Fabriken wandelte. In einem zweiten Schritt widmet sich der Text der Frage, wie Nikolaus II. Fabrikfotografien für seine Selbstinszenierung nutzte und welche Rolle der Krieg in diesem Zusammenhang spielte.

Quellengrundlage für die Untersuchung der visuellen Berichterstattung in Illustrierten bilden wie im Kapitel „Fabriken als Konsumartikel - Illustrierte Zeitschriften“ die fünf Zeitschriften Iskry, Niva, Ogonëk, Solnce Rossii und

Jörg Baberowski: Der Anfang vom Ende. Das Zarenreich im Ersten Weltkrieg, in: Osteuropa, Jg. 64/2014, Heft 2-4, S. 7-20, S. 9, 12; Alfons Brüning: Katastrophe und Epochenwende. Der Erste Weltkrieg und die Russisch Orthodoxe Kirche, in: Osteuropa, Jg. 64/2014, Heft 2-4, S. 263-278, S. 265-267; Jörg Baberowski: „Der Nationalismus ist ein mächtiges Gefühl“. Die russische Presse und der Ausbruch des Ersten Weltkriegs, in: Georg Eckert; Peter Geiss; Arne Karsten (Hrsg.): Die Presse in der Julikrise 1914. Die internationale Berichterstattung und der Weg in den Ersten Weltkrieg, Münster 2014, S. 61-82, S. 81-82.

8 Melissa Stockdale: Mobilizing the Nation. Patriotic Culture in Russia's Great War and Revolution, 1914-20, in: Murray Frame u. a. (Hrsg.): Russian Culture in War and Revolution, 1914-22. Book 2. Political Culture, Identities, Mentalities, and Memory, Bloomington 2014, S. $3-26$, S. 3 .

9 Siehe hierzu: in diesem Kapitel S. 349-36o.

10 Bernd Hüppauf: Medien des Krieges, in: Niels Werber; Stefan Kaufmann; Lars Koch (Hrsg.): Erster Weltkrieg. Kulturwissenschaftliches Handbuch, Stuttgart 2014, S. 311-339, S. 313 . 
Ženskoe Delo sowie die illustrierte Beilage der Tageszeitung Novoe Vremja," die von August 1914 bis zum Zeitpunkt ausgewertet wurden, an dem sie ihr Erscheinen einstellten. Analog zur Arbeitsmethode im Kapitel zu illustrierten Zeitschriften wurden zunächst alle illustrierten Artikel mit Bezug zu Fabriken in einer Tabelle erfasst, die Datum, Industriezweig und Ort vermerkte. Weiter wurde festgehalten, ob Menschen auf den Fotografien zu sehen waren, ob es sich um einen Text mit Illustrationen oder nur um eine Fotografie handelte. ${ }^{12}$

\subsection{Zeitschriften in Kriegszeiten}

Mit dem Beginn des Ersten Weltkriegs verfügte die Regierung des Zarenreichs eine militärische Zensur. ${ }^{13}$ Diese sollte sicherstellen, dass Journalisten und Redakteure gemäß der patriotischen Vorgaben berichteten und keine kriegswichtigen Details preisgaben, die möglicherweise dem Feind von Nutzen hätten sein können. Die Zensur galt auch für Illustrationen und Fotografien, so dass bei der Analyse von Zeitschriften der Kriegsjahre davon ausgegangen werden muss, dass staatliche Stellen deren Inhalte geprüft und genehmigt hatten. ${ }^{14}$ In Russland konzentrierte sich die Zensurbehörde besonders auf Aufnahmen von den Frontlinien und überwachte die Publikationen in der Hauptstadt vergleichsweise streng. ${ }^{15}$ In der Provinz wie auch in Moskau setzten die Behörden die Zensur hingegen weniger streng durch. ${ }^{16}$ Teilweise protestierten die Herausgeber gegen Restriktionen, indem sie die Spalten und Seiten der Zeitschriften unbedruckt ließen, auf denen die von der Zensurbehörde verbotenen Inhalte veröffentlicht worden wären. Dadurch führten sie ihren

11 Die Analyse diese Zeitschrift wurde durch Funde in weiteren russischen, englischen und französischen Journalen ergänzt, die stichprobenartig ausgewertet wurden.

12 Zur Methode der Bildanalyse in Illustrierten siehe: Kapitel „Fabriken als Konsumartikel Illustrierte Zeitschriften", S. 241-282.

13 Ruud: Fighting Words, S. 225.

14 Zur einer detaillierten Analyse des Umgangs mit der Zensur in Illustrierten in Deutschland, Frankreich und Großbritannien siehe: Ulrich Keller: Der Weltkrieg der Bilder. Organisation, Zensur und Ästhetik der Bildreportage 1914-1918, in: Fotogeschichte. Beiträge zur Geschichte und Ästhetik der Fotografie, Jg. 33/2013, Heft 130, S. 5-50.

15 Zu Details der Zensurbestimmungen siehe: Christopher Stolarski: Press Photography in Russia's Great War and Revolution, in: Murray Frame u. a. (Hrsg.): Russian Culture in War and Revolution, 1914-22. Book 1. Popular Culture, the Arts and Institutions, Bloomington 2014, S. 139-163, S. 146.

16 Stolarski: The Rise of Photojournalism, S. 179-180. 
Lesern das maßregelnde Eingreifen von staatlicher Seite vor Augen. ${ }^{17}$ Diese Praxis hielt an, bis die provisorische Regierung am 27. April 1917 alle Zensurmaßnahmen aufhob. ${ }^{18}$

Nach Ausbruch des Ersten Weltkriegs mussten viele russische Betriebe ihre Produktion zurückfahren oder einstellen, weil sie auf westeuropäische Importe von Rohstoffen oder Produkten angewiesen waren, die nun ausblieben. $\mathrm{Zu}$ den Mangelwaren gehörte auch Papier. Dies führte dazu, dass ein großer Teil der 3.00o Zeitungen und Zeitschriften, die vor dem Krieg existierten, sein Erscheinen einstellen musste. ${ }^{19}$ Trotz dieser Probleme bestanden die hier untersuchten Illustrierten alle bis mindestens 1917, sie mussten aber auf die Papierknappheit reagieren: Ab August 1914 verschwanden die Werbeteile aus den Illustrierten. ${ }^{20}$

Neben den Engpässen in der Papierversorgung litt die illustrierte Presse unter dem Ausbleiben ausländischer Importe fotografischer Ausrüstung und Zubehör sowie der benötigten Chemikalien, die nur noch schwer erhältlich waren. Russische Fotografen und Amateure mussten ihren Materialbedarf durch Produkte aus Westeuropa und den USA decken. Die schwierige Versorgungslage verschärfte sich zusätzlich, weil die Armee zunehmend Fotografien für die Kriegsführung nutzte. ${ }^{21}$ Als die Importe ausblieben, rief das Militär die Bevölkerung dazu auf, ihre private Fotoausrüstung für kriegswichtige Zwecke abzuliefern. ${ }^{22}$ Diese Appelle richteten sich in erster Linie an Privatpersonen. Kaum ein professioneller Fotograf dürfte freiwillig seine Existenzgrundlage aufgegeben haben. Diese Situation führte zu einem Rückgang an fotografischen Vorlagen für die Illustrierten, denn die Herausgeber hatten in der Vorkriegszeit gerne auf Aufnahmen von Amateuren

17 Beispielsweise: Žurnal kopejka, No. 9, 1915, Moskau, S. 4-5. Für dieses Kapitel wurden die Jahrgänge 1914 und 1915 dieser Zeitschrift ausgewertet.

18 Stolarski: The Rise of Photojournalism, S. 181-182.

19 Kask; Mochnačjova: Vvedenie, S. 33.

20 Im Juli 1916 publizierte Iskry einen Artikel über eine Papierfabrik in Finnland und betonte dabei, welch wichtigen Beitrag diese leiste, um trotz des Kriegs die Produktion von Zeitungen und Illustrierten sicherzustellen. o. A.: Bumažnyj korol', in: Iskry, 10.07.1916, S. 216.

21 Zum militärischen Nutzen der Fotografie siehe: Stefanie Klamm: Kriegslandschaften. Fotografie als Mess- und Aufklärungsinstrument, in: Ludger Drenthal; dies. (Hrsg.): Fotografie im Ersten Weltkrieg, Berlin 2014, S. 72-77; Hüppauf: Medien des Krieges, S. 324.

22 Barchatova: Wissenschaft? Handwerk? Kunst!, S. 35. Wie groß die Resonanz auf solche Aufrufe war, ist allerdings nicht bekannt. 
zurückgegriffen, um besonders über Ereignisse aus der Provinz möglichst zeitnah berichten zu können. ${ }^{23}$

Indem die Reklameteile aus den Illustrierten verschwanden, verloren die Industriellen die Plattform, auf der sie bis zum Kriegsausbruch ihre Unternehmen in Szene gesetzt hatten. Die meisten Industriefotografien waren in Werbeanzeigen abgedruckt worden. Dies war nicht der einzige Grund warum Fabrikfotografien zunächst aus russischen Zeitschriften verschwanden. Gerade in Kriegszeiten war es mit Blick auf die Zensur problematisch, Innenaufnahmen aus Betrieben anzufertigen und zu veröffentlichen, denn Fabriken waren Orte mit besonderer Wichtigkeit für die Kriegsführung. Dies galt besonders für Rüstungsbetriebe. Die russische Zensur war zwar weniger streng als die des deutschen Militärs, ${ }^{24}$ dennoch erschien in den Illustrierten keine Fotografie, die einer der großen russischen Waffenfabriken zugeordnet werden könnte.

Die russischen Redakteure nutzten mit Kriegsausbruch vermehrt das Angebot internationaler Bildagenturen oder ihrer Verbündeten Frankreich und Großbritannien, um den Mangel an lokalem Bildmaterial auszugleichen. ${ }^{25}$ Die begrenzte Anzahl an Fotografien hatte zur Folge, dass unterschiedliche russische Illustrierte dasselbe Motiv publizierten. ${ }^{26}$ Es ist bekannt, dass internationale Bildagenturen der Entente Fotografen an die russische Front schickten, um dort Bilder des militärischen Verbündeten aufzunehmen. ${ }^{27}$ Kaum untersucht ist jedoch, dass auch Illustrierte im Zarenreich vom Angebot ausländischer Bildagenturen und Händlern Gebrauch machten, um ihre Berichterstattung auf eine breitere Grundlage zu stellen. Gerade englische Agenturen waren besonders attraktive Bildlieferanten, da die Kriegszensur in Großbritannien vergleichsweise moderat ausfiel. Öffentliche Diskussion und Meinungsbildung hatten auf der Insel einen hohen Stellenwert und waren

\footnotetext{
23 Stolarski: Another Way of Telling the News, S. 568-569.

24 Keller: Der Weltkrieg der Bilder, S. 23.

25 Nicht nur im Zarenreich gab es einen Mangel an Bildern, auch in Deutschland hatten Herausgeber mit diesem Problem zu kämpfen. Als Reaktion druckten sie dieselben Fotografien in unterschiedlichen Kontexten ab. Ludger Derenthal; Stefanie Klamm: Bilderflut - Bildermangel. Fotografie im Ersten Weltkrieg, in: dies. (Hrsg.): Fotografie im Ersten Weltkrieg, Berlin 2014, S. 8-18, S. 14.

26 Beispielsweise eine Fotografie aus einer Werkshalle von Krupp: Niva, 9.12.1914, S. 951 und Žurnal kopejka, No. 1, 1915, S. 7; sowie von Arbeiterinnen in einer englischen Brauerei: o. A.: Ženščiny-rabočie na pivovarennom zavode v Anglii, in: Ogonëk, 08.05.16, S. 11 und o. A.: Ženščiny-rabočie na pivovarennych zavodach v Anglii, in: Ženskoe delo, 14.5.1916, S. 13 .

Stolarski: The Rise of Photojournalism, S. 185.
} 


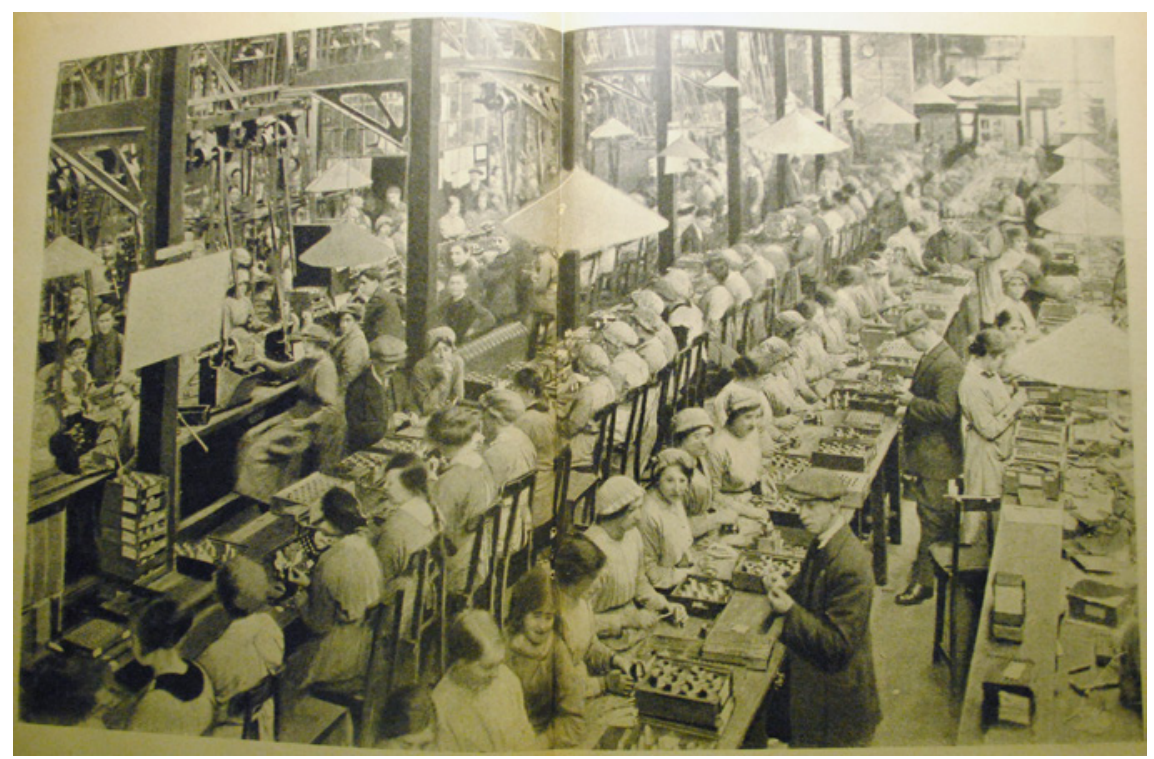

Abb. $71 \quad$ o. A.: Englische Arbeiterinnen in einem Betrieb bei der Fertigung von Granaten für die Armee (Anglijskija ženščiny na zavode za vydelkoj snarjadov dlja armii), in: Solnce Rossii, 10.03.1916, S. 8-9

auf gute Reportagen angewiesen. ${ }^{28}$ Die ausländischen Fotografien boten für russische Herausgeber den Vorteil, dass bereits eine Zensurbehörde die Aufnahmen genehmigt hatte. Die Redaktionen liefen somit nicht Gefahr, möglicherweise geheimes oder kriegswichtiges Bildmaterial zu veröffentlichen. Neben russischen machten selbstverständlich auch französische Redaktionen vom Angebot der britischen Kollegen Gebrauch; in unterschiedlichen Ländern erschienen identische Aufnahmen. Die Herausgeber wiesen den Bildern aber unterschiedliche Funktionen in den jeweiligen nationalen Narrativen zu, wie das folgende Beispiel zeigt.

Am 10. März 1916 druckte Solnce Rossii eine Fotografie aus einer englischen Fabrik (Abb. 71). Der anonyme Fotograf hatte seine Kamera vermutlich auf einem Gerüst platziert und hielt aus dieser erhöhten Perspektive die Fabrikhalle fest, in der Arbeiterinnen unter männlicher Aufsicht an langen Tischen Einzelteile zu Granaten zusammenmontierten. Die Bildunterschrift informierte die Leser, dass hier englische Frauen in einer Fabrik beim Zusammensetzen von Granatzündern zu sehen seien.

Das Bild entstand ursprünglich im Auftrag des englischen Ministry of Munition und war Teil einer Kampagne, mit der das Ministerium Fabrikbesitzer

28 Keller: Der Weltkrieg der Bilder, S. 37-38. 
davon überzeugen wollte, Frauen einzustellen, um den Arbeitskräftemangel in der Rüstungsindustrie zu beheben. ${ }^{29} \mathrm{Zu}$ diesem Zweck publizierte es eine illustrierte Broschüre, aus der die Aufnahme stammte. In den Dienst der Kampagne stellten sich auch verschiedene Zeitschriften. So druckten im Februar 1916 die Zeitungen The Daily Mail sowie The Graphic Fotografien aus dieser Kampagne auf Sonderseiten. ${ }^{30}$ The Daily Mail veröffentlichte die Aufnahme unter dem Obertitel "Was die Frauen für die Männer an der Front tun“, und die Bildunterschrift informierte den Leser darüber, dass in den meisten Fabriken, in denen Granaten hergestellt wurden, bereits Frauen die Maschinen bedienten. Auch die anderen Bildunterschriften betonen die wichtige Funktion von Arbeiterinnen in der Rüstungsindustrie, und welche Erfolge diese bereits erzielt hätten. Sie suggerierten somit, dass Frauenarbeit normal sei, und feierten das Engagement der Frauen für die Soldaten an der Front. Diese Darstellung widerspricht dem Vorwort der Publikation des Ministeriums. Dort betonte der Autor, dass die Veröffentlichung Fabrikbesitzer, die bislang skeptisch waren, ermutigen wolle, Frauen einzustellen. ${ }^{31}$ Es war folglich 1916 durchaus noch nicht normal, geschweige denn ein Faktum, dass überwiegend Frauen in der Rüstungsindustrie arbeiteten.

Während die englischen Zeitschriften nur Ausschnitte der Fotografie abdruckten, nutzte die französische Zeitschrift J'ai vu vergleichbar wie Solnce Rossii die Aufnahme zur Illustration einer ganzen Doppelseite. Der erläuternde Text ist der ausführlichste aller Begleitexte und ging darauf ein, wie die Frauen in der Rüstungsindustrie arbeiteten, während die Männer in der Armee dienten. Dabei schmückte der Autor die Beschreibung zusätzlich aus, indem er Beispiele aufführte, die beweisen sollten, dass die gesamte Gesellschaft sich an diesem Kampf beteiligte: Nebeneinander arbeiteten Lady, Schneiderin, Sekretärin, Hutmacherin und Witwe des auf dem Schlachtfeld gefallenen Soldaten. Die Beschreibung bemühte das Bild einer Gesellschaft, in der soziale Unterschiede angesichts der externen Gefahr für das Vaterland aufgehoben seien. Der Autor präsentierte den französischen Lesern einen Zustand, den diese aus ihrem Alltag im Jahr 1916 nicht kannten. Hatten sich in Frankreich zunächst alle Gruppen der französischen Gesellschaft der union sacré angeschlossen, nahmen mit zunehmender Dauer des Kriegs die

29 Gareth Griffiths: Women's Factory Work in World War I, Stroud 1991, S. 18. Zu dieser Kampagnen auch: Thom: Nice Girls and Rude Girls; Susan Grayzel: Women's Identities at War. Gender, Motherhood and Politics in Britain and France during the First World War, Chapel Hill, London 1999 .

30 In The Daily Mail erschienen die Bilder am 11.02.1916, S. 7, in The Graphic am 19.02.1916.

31 Ministry of Munition (Hrsg.): Notes on the Employment of Women, London 1916, S. 5. 
kritischen Stimmen zu. ${ }^{32}$ Die Bildunterschrift präsentierte auf diese Weise eine patriotisch vereinte Gesellschaft als imaginäres Vorbild.

Weiter schrieb der Autor, dass alle Frauen Englands dem französischen Beispiel gefolgt seien und nun ihren Teil zum finalen Sieg beitragen wollten. ${ }^{33}$ Der Autor erweckt hier den Anschein, Frauenarbeit sei in Frankreich bereits der anerkannte Normalfall. Es gab jedoch auch in der französischen Gesellschaft Vorbehalte gegenüber den neuen Arbeitskräften und Bedenken, dass die Fabrikarbeit den weiblichen Charakter verderben könnte. ${ }^{34}$ Außerdem suggeriert der Text mit dieser Formulierung, dass die Grande Nation ein Vorbild für den Nachbarn Großbritannien sei. Im englischen Originaltext des Ministeriums fanden sich jedoch weder Details zu den Berufen der Arbeiterinnen, noch erwähnte das Ministry of Munitions Frankreich als Vorbild für die Anstellung von Frauen in der Industrie. ${ }^{35}$

Das Beispiel zeigt, dass der Krieg Fotografien zu einem raren Gut machte, so dass russische Herausgeber auf Fotografien aus England oder Frankreich zurückgriffen. Mit der Grenzüberschreitung verloren die Bilder ihre ursprünglichen Verwendungskontexte. Die Redakteure passten die Fotografien in die jeweiligen nationalen Narrative ein und übertrugen ihnen neue Funktionen. Auf diese Weise vermittelten Abzüge desselben Negativs Menschen in verschiedenen Ländern unterschiedliche Botschaften.

\subsection{Neue Zeiten, neue Bilder}

Der Beginn des Ersten Weltkriegs veränderte die Inhalte illustrierter Zeitschriften. Bis 1914 waren Fotografien von Fabriken im redaktionellen Teil der russischen Illustrierten wenig präsent. Sie erschienen abgesehen von Reklameteilen besonders in Zusammenhang mit Unfällen. Dies änderte sich mit Kriegsbeginn, als nicht nur die Reklameteile, sondern auch die Meldungen über Fabrikunglücke aus den Zeitschriften verschwanden. Vor dem Hintergrund des

32 Stig Förster: Civil-Military Relations, in: Jay Winter; Charles Stille (Hrsg.): The Cambridge History of the First World War, Bd. 2. The State, Cambridge 2014, S. 91-125, S. 97-98.

33 J'ai vu am 06.05.1916, o. S.

34 Margaret H. Darrow: French Women and the First World War. War Stories of the Home Front, Oxford u. a. 2000, S. 187.

35 In Frankreich stieg der Anteil an arbeitenden Frauen in der Industrie bereits kurze Zeit nach Kriegsbeginn an, was auch daran lag, dass viele Frauen ihre Familien ernähren mussten. Hierzu beispielsweise: L. Capdevila u. a.: Sexes, genres et guerres. France, 1914-1945, Paris 22010, S. 61-63, 67; Laura Lee Downs: Manufacturing Inequality. Gender Division in the French and British Metalworking Industries, 1914-1939, Ithaca 1995, S. $48-49$. 
Kriegsgeschehens und der Berichte von der Front schien es den Herausgebern nicht wünschenswert, mit Meldungen und Bildern von Katastrophen auf zusätzliches Leid in der Heimat aufmerksam zu machen. ${ }^{36}$ Es ist nicht nachweisbar, dass diese Veränderungen auf Weisung der militärischen Zensur erfolgten, allerdings liegt dies im Bereich des Möglichen. ${ }^{37}$ Diese Meldungen hätten unweigerlich Fragen nach der Verwundbarkeit und Leistungskraft der russischen Industrie und folglich auch nach der militärischen Stärke des Zarenreichs aufgeworfen, was unbedingt vermieden werden sollte.

Stattdessen erfreuten sich Berichte und Fotoreportagen über Fabriken bei Journalisten und Redakteuren und somit wohl auch bei der Leserschaft zunehmender Beliebtheit. Zwischen August 1914 und 1917 erschienen mehr Artikel über Fabriken als in den vorangegangenen drei Jahren im Werbe- und redaktionellen Teil der Illustrierten zusammen. Statt der Unternehmer übernahmen nun Journalisten die Berichterstattung über die Industrie. Der Erste Weltkrieg war der erste Konflikt, der in russischen Zeitschriften für eine auffallende Zunahme an Berichten über Fabriken sorgte. Zwar veränderten sich die Themen in Illustrierten im Verlauf des Kriegsgeschehen sowohl während des Russisch-Osmanischen Kriegs (1877-1878) als auch während des Russisch-Japanischen Kriegs (1904-1905). ${ }^{38}$ In beiden Fällen legten die Herausgeber der Zeitschriften ihr Augenmerk jedoch auf die Ereignisse an der Front und auf die Soldaten. Die Darstellungen der Heimatfront oder der Rüstungsindustrie waren demgegenüber wenig präsent.

Nach 1914 verschob sich das Interesse der Redakteure auf neue Industriezweige. Während in der Vorkriegszeit besonders die Lebensmittel- und Luxusgüterindustrie in Illustrierten präsent gewesen waren, rückten nun Waffenfabriken in den Fokus. Dieses neue Interesse an der Rüstungsindustrie war bereits im Herbst und Winter des Jahres 1914 zu beobachten, verstärkte sich aber 1915 erheblich. Es umfasste sowohl illustrierte Berichte über russische als auch über französische und englische Fabriken. Allerdings sparten die Redakteure vermutlich aus Gründen der Zensur die großen russischen Waffenproduzenten aus.

$3^{6}$ In Großbritannien bemühte sich die Regierung ebenfalls, möglichst alle Unglücke zu verschleiern, die sich in Rüstungsunternehmen ereigneten, weil sie fürchtete, diese Meldungen könnten die gesellschaftliche Unterstützung für den Krieg herabsetzen. Angela Woollacott: On Her Their Lives Depend. Munitions Workers in the Great War, Berkeley 1994, S. 85 .

37 Ruud: Fighting Words, S. 225.

38 Stolarski: Another Way of Telling the News, S. 571-573; Stolarski: Press Photography in Russia's Great War, S. 154. 
Die neue Begeisterung für die Waffenproduktion stand in direktem $\mathrm{Zu}$ sammenhang mit dem Kriegseintritt des Zarenreichs. Es war für die russische Regierung wichtig, der Bevölkerung die militärische Stärke und moderne Ausrüstung der eigenen Armee in einem positiven Licht zu demonstrieren. Dies umso mehr, als sich bereits bald nach Kriegsbeginn zeigte, dass die staatlichen Fabriken nicht in der Lage waren, den sprunghaft gestiegenen Bedarf an Rüstungsgütern zu decken. Bis 1914 waren ausschließlich Staatsbetriebe für die Waffenproduktion zuständig gewesen, sie hatten jedoch Schwierigkeiten die Produktionsnormen zu erfüllen. Darüber hinaus waren die Vorgaben in den Vorkriegsjahren für die Materialschlacht ${ }^{39}$ des Ersten Weltkriegs zu niedrig angesetzt. ${ }^{40} \mathrm{Um}$ diesem Problem zu begegnen, erhielten 1914 vier privatwirtschaftliche Unternehmen Aufträge für Artillerie und Munition im Umfang von rund fünf Millionen Rubel. ${ }^{41}$ Aber auch diese Maßnahmen reichten nicht aus, um die Versorgungslage des Militärs ohne ausländische Importe zu sichern. ${ }^{42}$ Die Fotografien aus Rüstungsbetrieben in den Illustrierten suggerierten den Lesern hingegen eine ausreichende Waffenversorgung. Dies war umso wichtiger, da das Zarenreich seit Mitte des 19. Jahrhunderts zwei Kriege verloren hatte, was die Zeitgenossen als Demütigung empfanden. Gründe für die Niederlage im Krimkrieg waren unter anderem die fehlende Infrastruktur und damit einhergehende Defizite in der Versorgung und unzureichende Beweglichkeit der Truppen. Auf der Krim unterlag Russland den europäischen Mächten Frankreich und Großbritannien. Entsprechend größer war die Schmach 1905, als sich das Zarenreich gegenüber dem Japanischen Kaiserreich und damit einer asiatischen Macht geschlagen geben musste. Diese Ereignisse lagen 1914 noch nicht einmal zehn Jahre zurück, so dass den Herausgebern

39 Zur Genese des Begriffs „Materialschlacht“ als Bezeichnung für den Ersten Weltkrieg siehe: Christoph Jahr; Stefan Kaufmann: Den Krieg führen. Organisation, Technik, Gewalt, in: Niels Werber; Stefan Kaufmann; Lars Koch (Hrsg.): Erster Weltkrieg. Kulturwissenschaftliches Handbuch, Stuttgart 2014, S. 164-231, S. 182-184.

40 Haumann: Kapitalismus im zaristischen Staat, S. 77.

41 Peter Gatrell: Russia's First World War. A Social and Ecnomic History, Harlow u. a. 2005, S. 24. Es handelte sich dabei um folgende Fabriken: Putilovskie zavody (Putilovwerke), Zavod Lessner (Betrieb Lessner), Russkoe obščestvo dlja izgotovlenija snarjadov i voennych pripasov (Russische Gesellschaft zur Herstellung von Granaten und Munition) in Petrograd sowie der Brjanskij mašinostroitel'nyj zavod (Brjansker Maschinenfabrik).

Die mangelnde Versorgung mit Waffen nahm an manchen Frontabschnitten solche Ausmaße an, dass die Offiziere den Soldaten verboten das feindliche Feuer zu erwidern. Mindestens ebenso gravierend für die Soldaten war auch der fehlende Nachschub an Essen und Winterkleidung. Hierzu: Figes: Die Tragödie eines Volkes, S. 284-286. Zur mangelnden Versorgung mit Munition auch: Lewis H. Siegelbaum: The Politics of Industrial Mobilization in Russia, 1914-17, London, Basingstoke 1983, S. 24-39. 
der Zeitschriften besonders daran gelegen war, ihren Lesern die Stärke der russischen Streitkräfte und die der Verbündeten vor Augen zu führen. Wir werden diesen Krieg gewinnen - so die Nachricht der Bilder.

Die Probleme des mangelnden Nachschubs an Munition entschärften sich erst 1916, als die russische Wirtschaft wieder an Fahrt aufnahm ${ }^{43}$ und die Rüstungsindustrie im Zarenreich viermal mehr Waffen als Österreich-Ungarn und damit fast so viele wie Deutschland produzierte. ${ }^{44}$ Aber bereits 1915 bemühten sich Journalisten das Zarenreich als Kriegsmacht zu präsentieren, die ihren Bedarf an militärischer Ausrüstung aus eigener Produktion decken könne. Gleichzeitig thematisierten die Redakteure mit Fotografien der Rüstungsindustrie den neuen Charakter des industrialisierten Kriegs. In dem sie Produktionsstätten präsentierten, vermittelten sie den Lesern die veränderten Dimensionen des Konflikts abseits der grausamen Bilder vom Schlachtfeld. ${ }^{45}$

Der Kriegsausbruch brachte nicht nur Fotografien anderer Länder in die Illustrierten, er führte auch dazu, dass Fotografen neue Motive in ihr Repertoire aufnahmen. ${ }^{46}$ In der Vorkriegszeit druckten russische Zeitschriften kaum Produktfotografien, gezeigt wurde der jeweilige Herstellungsprozess. Nach Kriegsbeginn veröffentlichten Illustrierte Aufnahmen, die Produkte aus der Rüstungsindustrie gezielt inszenierten. Abbildung 72 zeigt einen Arbeiter, der neben einer mannshohen Granate steht. Im Hintergrund erkennt der Betrachter weitere Sprengkörper von ähnlicher Größe, die waagrecht übereinandergestapelt sind. Der Mann neben der Granate legt seine Hand an das Geschoss. Durch seine Hinwendung zu diesem lebenszerstörenden Sprengkörper entsteht eine Spannung im Bildaufbau.

Bisher nahmen Fotografen nur dann Menschen neben industriell gefertigten Produkten auf, wenn sie als menschliches Maßband fungierten. ${ }^{47}$ Diesen

43 David Stevenson: 1914-1918. The History of the First World War, London ${ }^{2}$ 2012, S. 235-237; Dale Rielage: Russian Supply Efforts in America during the First World War, Jefferson 2002. Besonders problematisch war neben der Produktion vor allem die Lieferung des Nachschubs an die Front. Häufig verhinderte die unzureichend ausgebaute Infrastruktur, dass der Nachschub schnell die Frontabschnitte erreichte, an denen er benötigt wurde. William Philpott: Attrition. Fighting the First World War, London 2014, S. 175, 177.

44 Sean McMeekin: The Russian Origins of the First World War, Cambridge 2011, S. 220.

45 Hüppauf: Medien des Krieges, S. 313.

46 Allerdings existieren auch Fotografien, die ganz der Bildtradition des 19. Jahrhunderts folgen und Werkstätten aus der Rüstungsindustrie zeigen, ohne dass die Fotografen neue Motive oder eine neue Bildsprache aufgriffen. Siehe beispielsweise: V. Z. Vešapuri: Na rubeže dvuch vekov. Nižegorodskoe povolž'e i volga na fotografijach M. P. Dmitrieva, Gor'kij 1988, Abb. 142-143, 145 .

Bärtschi-Baumann: Industriefotografie damals, S. 2. Siehe Abbildung 24. 


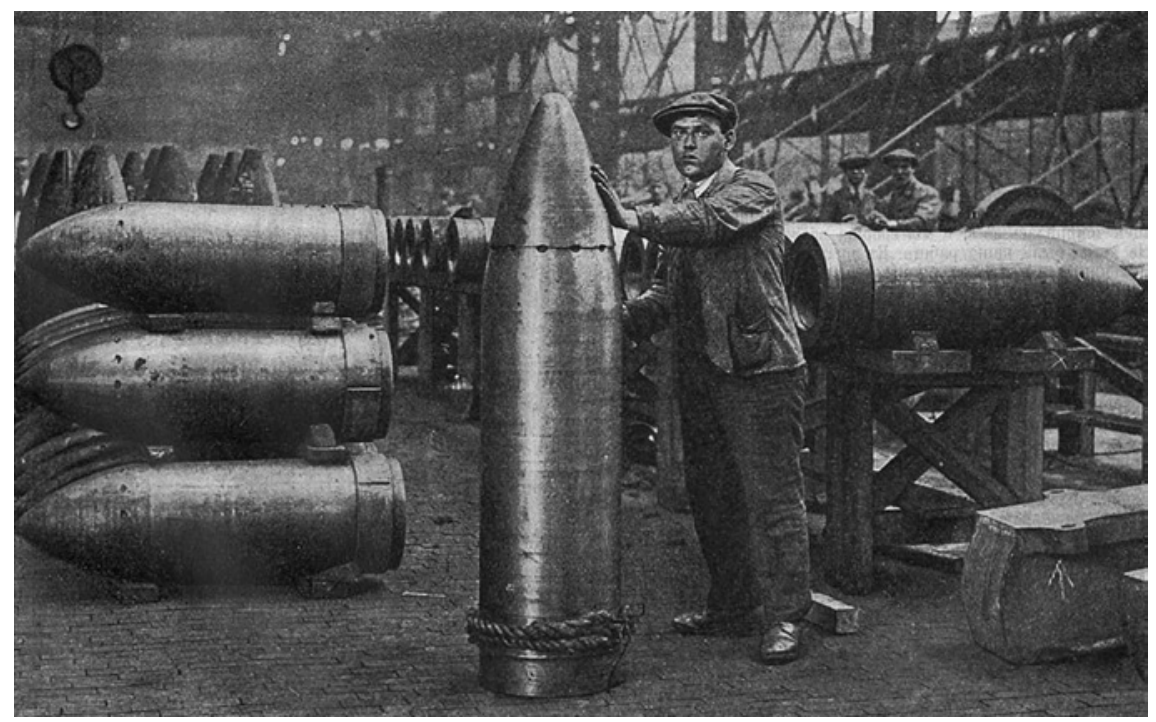

Abb. 72 o. A.: Eine mannshohe Granate (Snarjad pereros čeloveka), in: Niva, 24.09.1916, S. 651

Zweck erfüllt der hier abgebildete Arbeiter ebenfalls, darüber hinaus erweckt seine leicht vorgebeugte Haltung, mit der er der Granate näher kommt als unbedingt nötig, jedoch den Anschein, als verbinde beide eine besondere Beziehung. Indem sich der Hauptprotagonist des Bildes fast auf das Geschütz zu lehnen scheint, weckt er die Assoziation, als stütze er all seine Hoffnungen auf die Zerstörung des Feindes und den Schutz der Heimat auf diese Waffe. Diese Fotografie erinnert an das Titelblatt der französischen Illustrierten J'ai vu vom 16. April 1916, auf dem der französische Politiker Albert Thomas (1878-1932) zu sehen ist (Abb. 73).48

Thomas umfasst fast zärtlich eine mannshohe Granate und erzeugt damit ebenfalls eine Spannung zwischen den Thematiken Männlichkeit, Siegeshoffnung und Todesgefahr, die in der Inszenierung zusammenfallen. Diese

48 Der sozialistische Politiker Albert Thomas war während des Ersten Weltkriegs in Frankreich im Kriegsministerium für die Organisation der Rüstungsindustrie und der Industriearbeit allgemein verantwortlich. Barry Supple: War Economies, in: Jay Winter; Charles Stille (Hrsg.): The Cambridge History of the First World War, Bd. 2. The State, Cambridge 2014, S. 295-324, S. 312. Eine weitere Aufnahme, die diesen beiden im Bildaufbau gleicht, findet sich in: Niva, 28.05.1916. Zur Bedeutung und zum Wandel von Männlichkeitsbildern und Wahrnehmungen zu Beginn des Ersten Weltkriegs siehe auch: Christopher Clark: Die Schlafwandler. Wie Europa in den Ersten Weltkrieg zog, München 2013, S. 464-467. 
Abb. 73

o. A.: Die neueste Granate 400 von Albert Thomas (Le dernier nè d'Albert Thomas.

L'obus de 40o), in: J'ai vu ..., 16.4.1916 (neuer Stil), S. 1

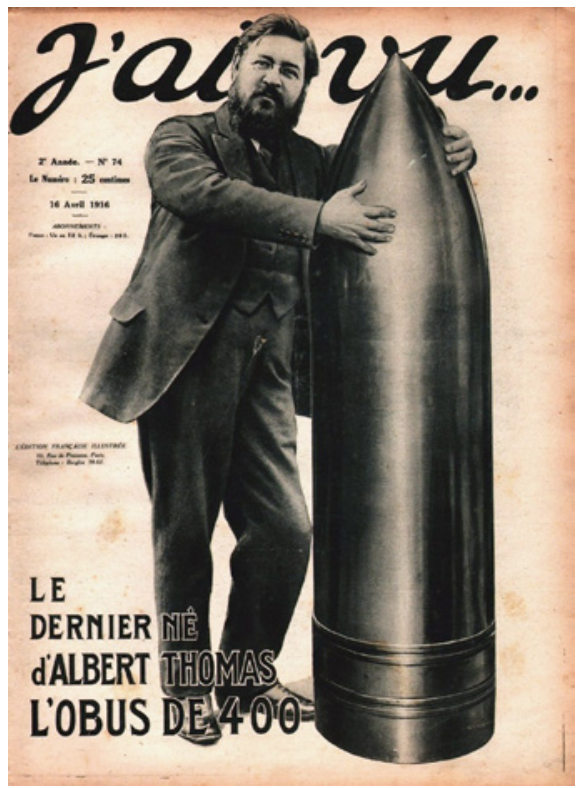

Form der visuellen Inszenierung von Waffentechnik und menschlicher Nähe war offenbar ein grenzüberschreitendes Phänomen. ${ }^{49}$

Eine andere Form der Produktfotografie inszeniert die schiere Masse der Produktion und eroberte ebenfalls nach 1914 die russischen Illustrierten. ${ }^{50}$ Besonders beeindruckend zeigt dies eine Seite aus der Illustrierten Iskry vom 12. Februar 1917 (Abb. 74) mit der Überschrift Otvet Anglii (Die Antwort Englands).

Das erste Bild oben links hält den Besuch des englischen Königs George V. $\left(1865^{-1936)}\right.$ in einer Waffenfabrik in Nottinghamshire fest. ${ }^{51}$ Die Fotografie zeigt im Vordergrund den Monarchen, der sich auf einen Stock stützt und frontal zum Betrachter steht. Neben und hinter ihm sind mehrere Menschengruppen und Einzelpersonen zu sehen. Die Linien der aufgeschichteten

49 Vor dem Ersten Weltkrieg galt in Deutschland und Großbritannien eine disziplinierte Form der Gewalt als fester Bestandteil des Männlichkeitsideals. Sonja Levsen: Elite, Männlichkeit und Krieg. Tübinger und Cambridger Studenten 1900-1929, Göttingen 2006, S. 100-104, 134-135.

50 Beispielsweise die Aufnahmen: o. A.: Na fabrike „Pobedy“ vo Francii. V voennych masterskich g. Liona, in: Ogonëk, 03.01.1916, S. 12.

51 Das Original im Imperial War Museum London: HU 96427. Der Fotograf Ernest Milner nahm dieses Bild in einerWaffenfabrik in Chilwell, Nottinghamshire, am 15. Dezember 1916 auf. 


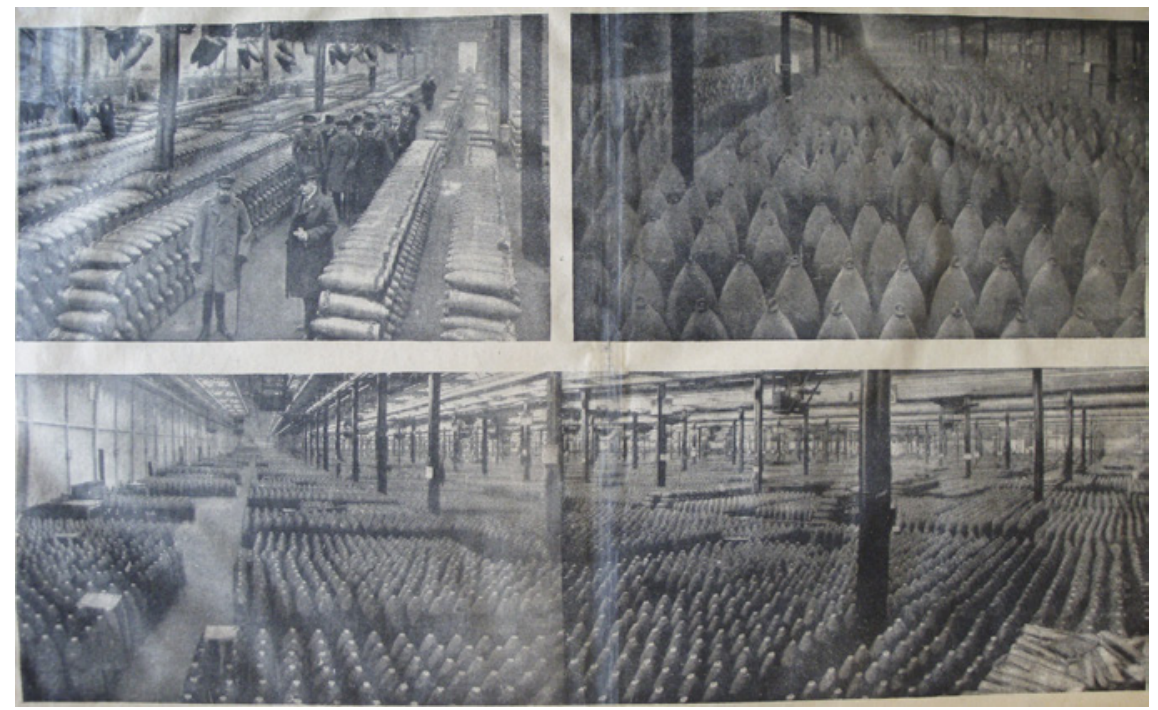

Abb. $74 \quad$ Ernest Milner: Die Antwort Englands (Otvet Anglii), in: Iskry, 12.02.1917, S. 50

Granaten ziehen sich vom Vordergrund bis an die Rückwand der Lagerhalle und strukturieren das Bild maßgeblich. Rechts im Hintergrund laufen sie auf eine geöffnete Türe zu, die sich hell vor der Rückwand des Arsenals abzeichnet. Sie stellt den Ausgang aus dem Waffenlager dar und symbolisiert die Verbindung zum Schlachtfeld, für das die tödliche Produktion vorgesehen ist. ${ }^{52}$

Indem dieses Bild oben links auf der Doppelseite steht, ist für den Betrachter deutlich, dass es den Beginn des visuellen Narrativs bildet und damit den im Vordergrund abgebildeten George V. zum Hauptprotagonisten macht. Obwohl er auf den beiden anschließenden Fotografien nicht zu sehen ist, wird deutlich, dass er auch die Befehlsgewalt über die hier abgebildeten Sprengkörper hat. Die weiteren beiden Aufnahmen zeigen menschenleere Lagerhallen mit geometrisch aufgestellten Granaten. Die geometrische Inszenierung von Industrieprodukten war in den Vorkriegsjahren in Alben und Festschriften verbreitet. Die russischen Illustrierten erreichte sie erst in den Kriegsjahren, wobei der Fotograf in diesem Fall die geometrische Inszenierung ins Extrem trieb und dadurch eine neue Aussage formulierte: ${ }^{53}$ Es ging nicht darum, eine Werkshalle zu zeigen, in der symmetrisch aufgeschichtete Produkte den positiven, ordentlichen und sauberen Gesamteindruck einer Fabrik unterstützen sollten.

$5^{2} \quad$ Zur Bedeutung der Türe in der Kunst: Claude Gandelman: Reading Pictures, Viewing Texts, Bloomington, Indianapolis 1991, S. 48-53.

53 Zur Ästhetisierung von Maschinen und Produkten: Rahner: Glanzbilder, S. 12. 
Der gesamte Raum besteht aus den Produkten, den Granaten. Anders als im ersten Bild vermitteln die beiden Aufnahmen den Eindruck eines unendlich großen Raums, bestehend nur aus Geschützen und den Pfeilern der Lagerhalle. Die Fotografien unterstreichen das Ausmaß der „Antwort Englands“. Glaubten die Betrachter den Aufnahmen, so lagerte in Großbritannien ein schier unerschöpflicher Waffennachschub für die englischen Truppen und damit ein Garant für den Sieg der Entente und des Zarenreichs.

Die analysierten Beispiele stammen aus dem Jahr 1917, doch bereits Anfang 1916 druckte Ogonëk ähnliche Fotografien. ${ }^{54}$ Diese Form der Produktfotografie entwickelten Fotografen aus dem Wissen heraus, dass der Mangel an Munition ein essentielles Problem darstellte. Bereits Ende 1914 wurde deutlich, dass sich der Konflikt zu einem Stellungskrieg und damit zu einer Materialschlacht entwickeln würde..$^{55}$ Indem die Truppen immer mehr Munition benötigten, wuchs die Bedeutung der "Heimatfront" ${ }^{46}$ der auch russische Illustrierte entsprechende Aufmerksamkeit schenkten. Die russischen Journalisten präsentierten ihren Lesern hoffnungsmachende Nachrichten, patriotische Aufrufe sowie positive Berichte über den Produktionsalltag in den Fabriken. Alle Kriegsparteien hatten Probleme, den Verlust an männlichen Arbeitskräften auszugleichen. Insgesamt waren während des Ersten Weltkriegs im Zarenreich rund 40 Prozent der männlichen wehrfähigen Bevölkerung (zwischen 18 und 60 Jahre) in der Armee. ${ }^{57}$ Viele vakante Arbeitsplätze in der Industrie übernahmen darum für die Dauer der Kämpfe Frauen. ${ }^{58}$ Allerdings organisierte die russische Regierung keine staatlichen Kampagnen, die mit denen in Großbritannien vergleichbar gewesen wären. Die Journalisten und Redakteure erzeugten dennoch mit ihren Reportagen den Eindruck, als beteiligten sich alle Schichten der Bevölkerung am Krieg, entweder im Schützengraben oder an der Heimatfront. Entsprechend druckten die Illustrierten Berichte über

o. A.: Na fabrikach „Pobedy“ vo Francii.

55 Stephane Audoin-Rouzeau: Combat and Tactics, in: Jay Winter; Charles Stille (Hrsg.): The Cambridge History of the First World War, Bd. 2. The State, Cambridge 2014, S. 151-173, S. 153-154. Dies erklärt auch, warum Berichte über Waffenfabriken erst mit einer gewissen Verspätung solch große Popularität erlangten - nämlich erst zu einem Zeitpunkt, als die Versorgungsengpässe nicht mehr zu übersehen waren. Ruth Amende Roosa: Russian Industrialists during World War I. The Interaction of Economics and Politics, in: Gregory Guroff; Fred Varstensen (Hrsg.): Entrepreneurship in Imperial Russia and the Soviet Union, Princeton 1983, S. 159-187, S. 162.

56 Zum Zarenreich: Gatrell: Russia's First World War, S. 24, 33.

57 Peter Gatrell: Poor Russia, Poor Show. Mobilising a Backward Economy for War, 1914-1917, in: Stephen Broadberry; Mark Harrison (Hrsg.): The Economics of World War I, Cambridge 2005, S. 235-275, S. 251.

$5^{8}$ Manfred Hildermeier: Die Russische Revolution, 1905-1921, Frankfurt a. M. 1989, S. 117. 
Werkstätten, die in Gefängnissen eingerichtet worden waren, ${ }^{59}$ Meldungen über die Mobilisierung höherer Lehreinrichtungen ${ }^{60}$ sowie Reportagen, wie sich Frauen ${ }^{61}$ und Kinder ${ }^{62}$ im Zarenreich bei der Produktion von Kriegsgütern einbrachten. Besonders die Zeitschrift Ogonëk publizierte regelmäßig Fotoseiten, die sich dem Kriegsalltag in der russischen Hauptstadt widmeten und oft speziell die Arbeit der Frauen würdigten. Dabei blendeten die Berichte aus, dass viele Arbeiter den neuen Kolleginnen mit Misstrauen und Ablehnung begegneten und sie als Eindringlinge in eine Männerdomäne sahen. ${ }^{63}$

Während des Ersten Weltkriegs zeigten die in Illustrierten publizierten Fotografien von Maschinen, Werkshallen und Produkten öfter Menschen als vor 1914 (Abb. 71). Die Bedeutung der Leistungsfähigkeit einer Fabrik vermittelten bisher Aufnahmen von Maschinen. Die Herausgeber gaben diese Darstellungsweise zugunsten einer patriotischen Erzählung auf: In diesem Narrativ waren nicht die Maschinen, sondern die arbeitenden Menschen die Hauptpersonen. Ab Juli 1915 traten Fotografien von Arbeiterinnen in der Rüstungsindustrie als neues Motiv in russischen Illustrierten auf. Die erste dieser Aufnahmen erschien in der Novoe Vremja (Abb. 75). ${ }^{64}$

Das Bild ist der klassischen Zentralperspektive folgend aufgebaut und gibt dem Betrachter zentral den Blick bis ans Ende der Produktionshalle frei. Rechts und links des Mittelganges zeigt die Fotografie Frauen, die an Werkbänken stehen und Granaten herstellen. Wie zahlreiche ähnliche Aufnahmen,

59 Beispielsweise: o. A.:Tjurmenyja masterskija, in: Iskry, 26.04.1915, S. 126; Popovskij: Raboty na nuždy zaključennych v Ljtovskom zamke i v ženskoj tjurme v Peterburge, in: Ogonëk, 28.02.1916, S. 15. Außerdem wurden auch habsburgische und deutsche Kriegsgefangene eingesetzt, um den Mangel an Arbeitskräften aufzufangen. Allerdings arbeiteten diese weniger in St. Petersburg und Moskau, wo die Zeitschriften erschienen, sondern beispielswiese beim Bau der Murmanbahn. Dabei kamen von 70.00o eingesetzten Soldaten (in erster Linie aus Österreich-Ungarn) etwa 25.00o ums Leben. Heather Jones: Prisoners of War, in: Jay Winter; Charles Stille (Hrsg.): The Cambridge History of the First World War, Bd. 2. The State, Cambridge 2014, S. 266-294, S. 282; Klaus Gestwa: Zum historischen Ort der Murmanbahn. Aspekte der Lager-, Eisenbahn- und Fotogeschichte, in: Evamarie Blattner; Nils Büttner; Wiebke Ratzeburg (Hrsg.): Der fotografierte Krieg. Der Erste Weltkrieg zwischen Dokumentation und Propaganda, Tübingen 2014, S. 152-165.

6o Beispielsweise: Štejnberg: Mobilizacija techničeskich sil vysšich učebnych zavednij, in: Ogonëk, 28.o6.1915, S. 12.

61 Beispielsweise: o. A.: Russkija ženščiny na zavodach, izgotovljajiščich snarjady, in: Ženskoe delo, 15.04.1916, S. 15 .

62 Beispielsweise: Popovskij: Deti vmesto vzroslych v Petrograde, in: Ogonëk, 24.08.1916, S. 16.

63 Herrlinger: Worker Culture(s) during War and Revolutions, 1914-20, S. 68-69.

64 o. A.: Voenno-promyšlennaja mobilizacija v Anglii, in: Novoe Vremja, 11.07.1915, S. 11. 


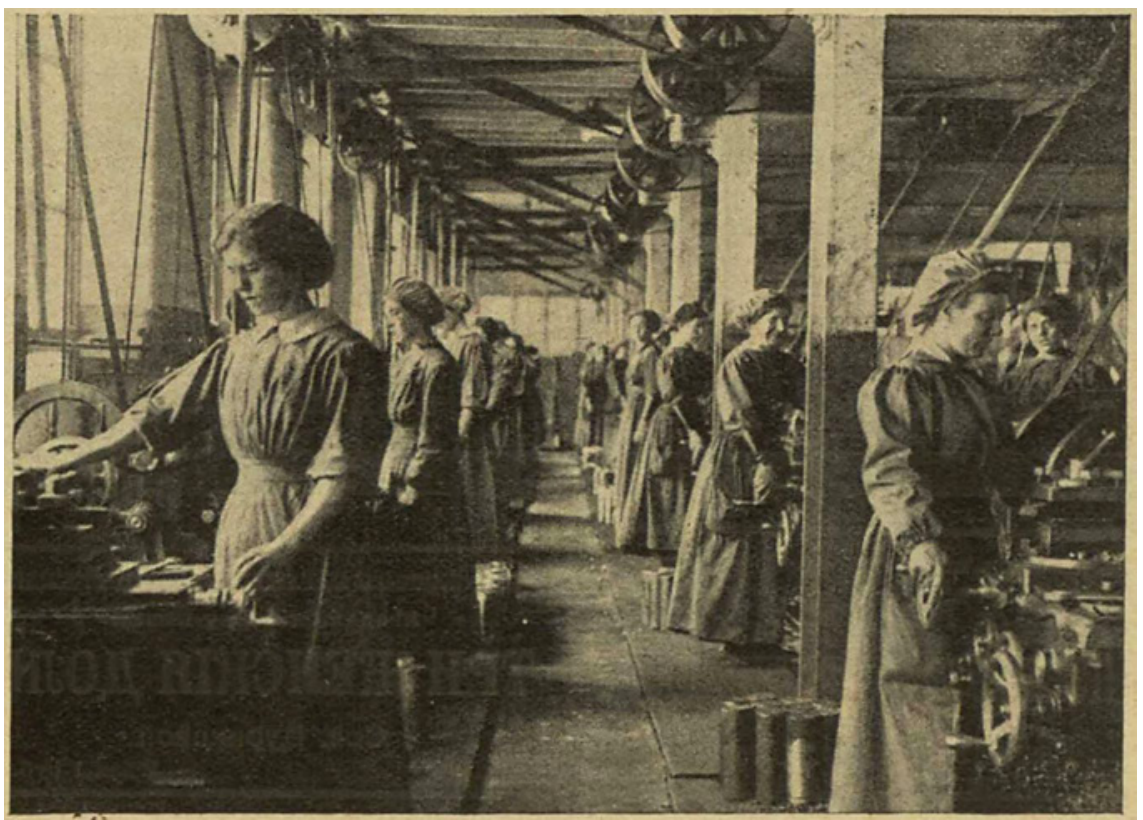

Abb. 75

o. A.: Die kriegsindustrielle Mobilisierung in England. Frauen an der Arbeit in einer Werkstatt, in der Granaten hergestellt werden (Voenno-promušlennaja mobilizacija v Anglii. Ženščiny na rabote v masterskoj, gde vydelyvajut'sja snarjady), in: Novoe Vremja, 17.07.1915, S. 11

die in den folgenden Monaten und Jahren erschienen, stammte die Aufnahme der Bildüberschrift nach aus Großbritannien. ${ }^{65}$

Bei Fotografien von Frauen handelte es sich nicht um ein völlig neues Motiv, wie teilweise in der Forschung behauptet wurde. ${ }^{66}$ In der russischen Industriefotografie erschienen bereits vor 1914 Arbeiterinnen auf Fotografien und zwar sowohl in Firmenalben als auch in Illustrierten; zumeist in Zusammenhang mit Berichten über die Tabak-, Textil- oder Nahrungsmittelindustrie. ${ }^{67}$ In den

65 Gerade bei diesen Motiven mussten die Redakteure offenbar auf einen überschaubaren Pool an Bildern zurückgreifen, denn mehrfach druckten russische Illustrierte identische Fotografien ab. Beispielsweise erschien eine Illustration von Frauen in einer englischen Fabrik in: Ogonëk, 12.07.1915, S. 16; Žurnal-kopejka, No. 339, 1915, S. 3 (für dieses Kapitel wurden die Monate Juli bis Dezember 1915 ausgewertet); Niva, 29.08.1915, S. 665; Ženskoe delo, 15.03.1916, S. 7 .

66 Lüdtke: Gesichter der Belegschaft, S. 82-83.

67 Es wäre lohnenswert zu untersuchen, wie präsent Darstellungen von weiblichen Arbeitskräften in der westeuropäischen oder amerikanischen Industriefotografie waren, denn die Beobachtung, dass Frauen bis Kriegsbeginn kaum präsent sind, beruht auch darauf, dass viele Autoren sich in ihren Untersuchungen besonders der Schwerindustrie widmen, 
Vorkriegsjahren war jedoch nicht nur im Zarenreich die Haltung gegenüber den Industriearbeiterinnen eher zwiespältig bis ablehnend. ${ }^{68}$ Vielen Zeitgenossen erschien es gefährlich und unzüchtig, Frauen alleine in die Stadt zum Arbeiten gehen zu lassen - es fehle ihnen die starke, männliche Hand, die sie durch die neue Umgebung leiten könne. ${ }^{69}$ Vor dem Hintergrund der kriegerischen Auseinandersetzungen etablierten sich neue Narrative und Bedeutungen für die Rolle und die Abbildungen von Arbeiterinnen.

Neu war für Fotografen und Betrachter das Motiv der Frauen in der Rüstungsindustrie. Die metallverarbeitende Industrie war bis zum Ersten Weltkrieg weitgehend eine Männerdomäne gewesen. Ähnlich wie in Deutschland, Frankreich und Großbritannien stellten auch russische Unternehmer im zweiten Kriegsjahr Frauen an, um den Mangel an Arbeitskräften aufzufangen. ${ }^{70}$ Das Publikum war nicht mit diesem Anblick vertraut, und die Fotografien von Arbeiterinnen in der Waffenproduktion hatten noch den Reiz des Ungewöhnlichen. Frauen, deren klassische Rolle in militärischen Konflikten diejenige der fürsorglichen Krankenschwester gewesen war, ${ }^{71}$ erschienen nun in den Zeitschriften in Zusammenhang mit der zerstörerischen Kraft der Waffen. ${ }^{72}$

wo nur wenige Arbeiterinnen tätig waren. Auch in der russischen Fabrikfotografie sind Aufnahmen von Arbeiterinnen stark branchenabhängig und am häufigsten in Bereichen zu finden, in denen auch ein großer Teil der Belegschaft Frauen waren, wie in der Textiloder Lebensmittelindustrie.

68 Zu Großbritannien siehe: Thom: Nice Girls and Rude Girls, S. 79.

69 Engel: Between the Fields and the City, S. 65-66.

70 Hildermeier: Die Russische Revolution, S. 117.

71 Hierzu: Rudolf Jaworski: Zur Internationalisierung politischer Bildwelten im Ersten Weltkrieg - am Beispiel russischer Propagandapostkarten, in: Geschichte in Wissenschaft und Unterricht, Jg. 63/2012, Heft 7-8, S. 465-477, S. 470-471; Thomas Flemming; Bernd Ulrich: Heimatfront. Zwischen Kriegsbegeisterung und Hungersnot - wie die Deutschen den Ersten Weltkrieg erlebten, München 2014, S. 219-227; Margaret R. Higonnet: At the Front, in: Jay Winter; Charles Stille (Hrsg.): The Cambridge History of the First World War, Bd. 3. Civil Society, Cambridge 2014, S. 121-152, S. 126-127, 130-132; Joshua A. Sanborn: Imperial Apocalypse. The Great War and the Destruction of the Russian Empire, Oxford 2014, S. 143-150; Joanna Bourke: Gender Roles in Killing Zones, in:Jay Winter; Charles Stille (Hrsg.): The Cambridge History of the First World War, Bd. 3. Civil society, Cambridge 2014, S. 153-177, S. 160-162. Zur ambivalenten Darstellung der Krankenschwestern zwischen Schwester und Lustobjekt siehe: Rudolf Jaworski: Mütter - Liebchen - Heroinen. Propagandapostkarten aus dem Ersten Weltkrieg, Köln, Weimar, Wien 2015, S. 119-130.

72 Neben den Arbeiterinnen stellten die Einheiten russischer Soldatinnen das vielleicht bekannteste Beispiel von der Aufhebung und Umkehrung bis dahin gängiger Rollenbilder dar. Hierzu: Dan Healey: Love and Death. Transforming Sexualities in Russia, 1914-22, in: Murray Frame u. a. (Hrsg.): Russian Culture in War and Revolution, 1914-22. Book 2. Political Culture, Identities, Mentalities, and Memory, Bloomington 2014, S. 151178, S. 166-168; Melissa Stockdale: „My Death for the Motherland Is Happiness“. Women, 
Neben dem neuen Motiv von Arbeiterinnen bei der Produktion von Sprengkörpern erschienen auch Fotografien, die einen neuen Bildaufbau und eine neue Bildsprache verwendeten. Jörn Leonhards Beobachtung, dass der Erste Weltkrieg kein „kultureller Frühling des 20. Jahrhunderts“, sondern „eine Spätblüte des 19. Jahrhunderts"73 war, trifft auf die Industriefotografien in russischen Zeitschriften nicht zu. Ganz im Gegenteil lässt sich hier eine visuelle Aufwertung der Arbeiterinnen beobachten, die über ihre reine Anwesenheit auf den Bildern weit hinausgeht. Ab 1915 zeigten die Aufnahmen häufig nicht mehr nur Werkshallen voller Menschen (Abb. 71 und 75), sondern Portraits von Einzelpersonen, insbesondere von Frauen (Abb. 76$).{ }^{74}$

Abb. 76

o. A.: Die Mobilisierung von Frauen in England. Die Herstellung von Patronenhülsen (Ženskaja mobilizacija v Anglii. Fabrikacija gil'z dlja patronov), in: Ženskoe Delo, 15.08.1915, S. 11

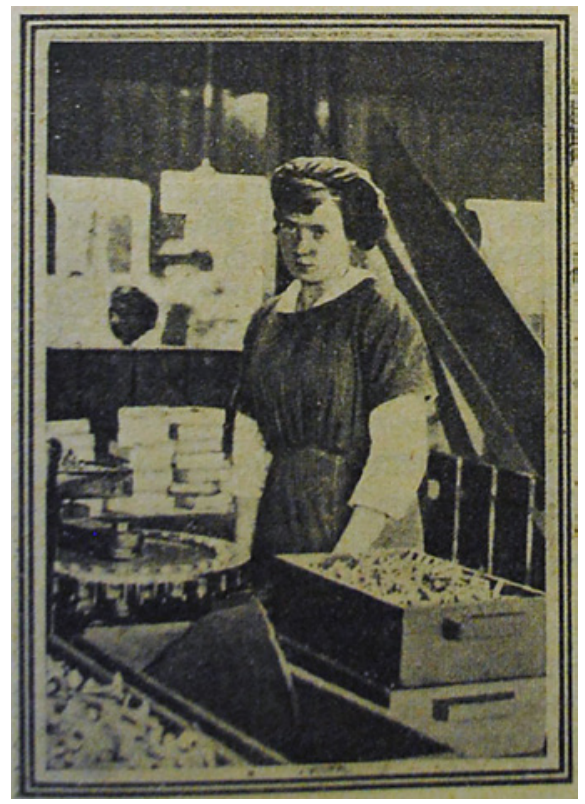

Patriotism, and Soldiering in Russias's Great War, 1914-1917, in: The American Historical Review, Jg. 109/2004, Heft 1, S. 78-116; Laurie Stoff: They Fought for the Motherland. Russia's Women Soldiers in World War I and the Revolution, Lawrence 2006.

73 Jörn Leonhard: Die Büchse der Pandora. Geschichte des Ersten Weltkriegs, München 2014, S. 601.

74 Zwischen der Jahrhundertwende und dem Kriegsausbruch 1914 waren Arbeiterportraits in russischen Illustrierten eine absolute Ausnahme. Ein Beispiel war der Bericht über Arbeiterinnen in Fabriken in Ženskoe delo aus dem Jahr 1910. Die an Frauen gerichtete Zeitschrift berichtete über die Ingenieurin Anna Tichonova. Hier war es für die Journalisten wichtig, ihre Hauptprotagonistinnen als Person abzubilden, weswegen sie in einer der Fotografien auf das Genre des Portraits zurückgriffen. A. Daurskij: Na praktičeskich rabotach, in: Ženskoe delo, 24.01.1910, S. 9-11. 


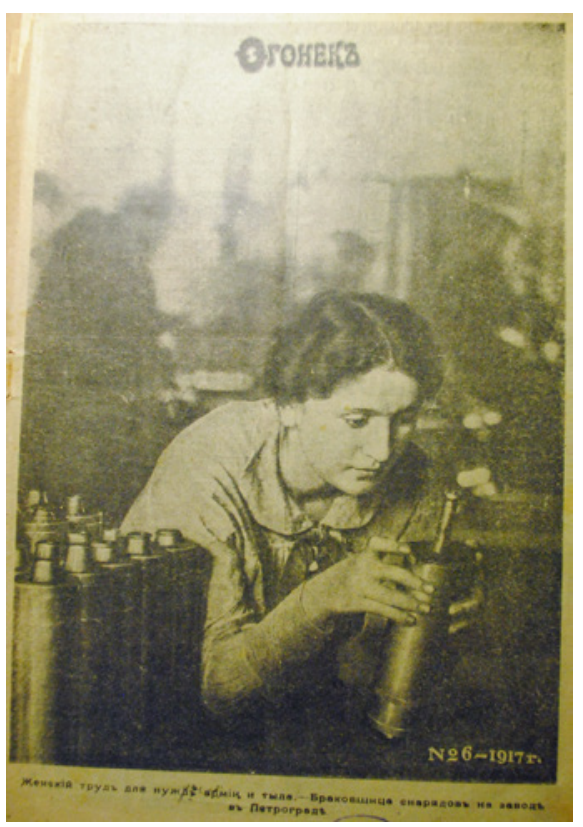

Abb. 77

o. A.: Frauenarbeit für die Bedürfnisse der Armee und die Heimat. Warenbeschauerin von Granaten in einem Betrieb in Petrograd (Ženskij trud dlja nuždy armii i tyla. Brakovščica snarjadov na zavode v Petrograde), in: Ogonëk, 05.02.1917, S. 1

Abbildung 76 zeigt exemplarisch, wie der Fotograf auf eine Person fokussierte, sie bei der Aufnahme an ihrem Arbeitsplatz ins Zentrum des Bildes rückte. Damit erhält sie die ungeteilte Aufmerksamkeit des Betrachters. Außerdem reduzierten Fotografen zunehmend den Abstand zwischen der Bildunterkante beziehungsweise dem Betrachter und dem fotografierten Objekt (Abb. 77). Auf Abbildung 76 vom August 1915 dominierten noch Kisten mit Werkstücken den Vordergrund und drängten die Hauptperson in den Mittelgrund ab. Hingegen zeigt Abbildung 77 die Arbeiterin im Vordergrund. ${ }^{75}$ Der Bildaufbau lenkt die Aufmerksamkeit auf die Frau und lässt im Betrachter das Gefühl entstehen, unmittelbar in der Situation anwesend zu sein. Somit verstärkt sich die Empathie gegenüber der Fotografierten.

Diese neue Bildsprache gebrauchten zunächst englische und französische Fotografen. Russische Fotografen orientierten sich an diesen Vorlagen und bald erschienen auch Portraits russischer Arbeiterinnen (Abb. 77). Die Herausgeber kombinierten diese Aufnahmen mit Fotografien anderer Gesellschaftsbereiche,

75 Einen ähnlichen Bildaufbau zeigt ein Plakat für russische Kriegsanleihen. Jaworski: Mütter - Liebchen - Heroinen, S. 113-115. 
in denen Frauen Männer bei der Arbeit ersetzten: beispielsweise beim Fahren von Straßenbahnen oder beim Feuerlöschen. ${ }^{76}$

Die Portraits zeigten zumeist ordentlich frisierte Frauen, deren Lächeln als Beweis dafür gelten konnte, dass sie sich gerne für das Vaterland engagierten. Auf Abbildung 77 zeigt der Fotograf die Protagonistin ohne Schutzhaube, die üblicherweise zur Arbeitskleidung in der Rüstungsindustrie gehörte, was ihr adrettes Aussehen unterstreicht. Die Aufnahme präsentiert ein geschöntes, fast friedliches Gesicht des militärischen Konflikts, das im Gegensatz zur Erfahrung der meisten Leser stand, die 1917 in der einen oder anderen Form persönlich vom Kriegsgeschehen betroffen waren. Die weichen Gesichtszüge der Frau machen vergessen, dass der Tod in Form der Granate auf der Fotografie unmittelbar anwesend ist. Allerdings galt dieser Tod dem Feind und Aggressor, der seine Vernichtung selbst heraufbeschworen hatte. Fast zärtlich blickt die Frau auf den Sprengkörper in ihrer Hand und verdrängt dadurch die Zerstörungskraft des Geschützes aus dem Bild.

Diese und vergleichbare Fotografien schönten die Verhältnisse, unter denen gerade Frauen in Munitionsfabriken tätig waren. Ihre Arbeit war körperlich sehr anstrengend und gefährlich. Besonders nachdem 1915 die russische Regierung das Nachtarbeitsverbot für Frauen und Kinder aufgehoben hatte, ${ }^{77}$ sahen sich die Arbeiterinnen mit größeren Belastungen und dadurch einer erhöhten Unfallgefahr konfrontiert. ${ }^{78}$ Außerdem waren sie häufig gesundheitsschädlichen und hochentzündlichen Chemikalien ausgesetzt. ${ }^{79}$ Maureen Hupfer führt diese beschönigende Darstellung darauf zurück, dass es nicht der kunstgeschichtlichen Tradition entsprochen habe, den schweren Arbeitsalltag der Frauen zu zeigen. ${ }^{80}$ Dies gilt jedoch nicht nur für Fotografien von Frauen, sondern es handelt sich hier um eine allgemeine Spezifik der Industriefotografie. In diesem Genre war es auch vor dem Ersten Weltkrieg niemals üblich, den gefährlichen und beschwerlichen Arbeitsalltag in Fabriken realistisch darzustellen. Im vorliegenden Fall war außerdem entscheidend, dass die Bilder in den Illustrierten Frauen motivieren sollten, ihren persönlichen Beitrag

76 o. A.: Ženščina vmesto mužčiny, in: Ogonëk, 30.08.1915, S. 15. Hier unterschieden sich russische von britischen Illustrierten. Letztere erzeugten den Eindruck, als wären Frauen fast ausschließlich in der Rüstungsindustrie tätig und ersetzten hier deutlich mehr Männer, als dies in Wirklichkeit der Fall war. Thom: Nice Girls and Rude Girls, S. 88.

77 Hildermeier: Die Russische Revolution, S. 120.

78 Downs: Manufacturing Inequality, S. 50.

79 Siegfried Köhler: Die russische Industriearbeiterschaft von 1905-1917, Dresden 1921, S. 96; Woollacott: On Her Their Lives Depend, S. 84.

8o Maureen Hupfer: A Pluralistic Approach to Visual Communication. Reviewing Rhetoric and Representation in World War I Posters, in: Advances in Consumer Research, Jg. 24/1997, Heft 1, S. 322-327, S. 325-326. 
zum Schutz des Vaterlandes zu leisten. Es wäre kontraproduktiv gewesen, die negativen Seiten der Fabrikarbeit besonders zu betonen.

Trotz dieser versteckten Propaganda ist davon auszugehen, dass sich die Mehrheit der Frauen nicht aufgrund ihrer patriotischen Gefühle entschied, eine Anstellung in einer Munitionsfabrik anzunehmen. Zeitgenössische Berichte betonten, dass gerade Frauen aus einfacheren Verhältnissen auf den Verdienst angewiesen waren, um ihre Familie ernähren zu können, während der Mann als Soldat diente. ${ }^{81}$ Obwohl sie weniger verdienten als Männer, waren die Löhne in der metallverarbeitenden Industrie 1916 mit durchschnittlich 35,30 Rubel im Monat in Moskau doppelt so hoch wie in der Textilindustrie. ${ }^{82}$ Allerdings fraß die enorme Teuerung große Teile dieses Verdienstes auf, so dass die Realeinkommen während der Kriegsjahre deutlich zurückgingen. ${ }^{83}$ Diese Sachlage verschwiegen die Journalisten in ihren Bildunterschriften und Texten, sie hätte die Erzählung des patriotischen Engagements an der Heimatfront untergraben.

Obwohl patriotische Narrative eine große Bedeutung in der Presse hatten, muss bei der Interpretation der Bilder berücksichtigt werden, dass illustrierte Zeitschriften auch während des Ersten Weltkriegs Konsumprodukte blieben: Fotografien übernächtigter, ausgemergelter Frauen fanden mit Sicherheit weniger Käufer als Portraits zurechtgemachter, ihre Weiblichkeit durch Frisur und Kleidung betonende Arbeiterinnen - zumal diese auch sexuelle Konnotationen transportierten. ${ }^{84}$ Außerdem hielten die Herausgeber mit den adretten Werktätigen an einem betont weiblichen Image der Frauen fest. Diese hübschen Damen würden keinem Kriegsheimkehrer seinen Arbeitsplatz streitig machen, sondern sich ganz der patriarchalen Tradition und Gesellschaftsordnung beugen und sich ohne zu murren wieder der Familie und dem Haushalt widmen, so die Botschaft. ${ }^{85}$

Die Journalisten verbanden das individuelle Engagement der Arbeiterinnen in ihren Begleittexten zu den Fotografien mit der militärischen Stärke

81 A. L'vova: Žesnkij trud vo vremena vojny, in: Professional'nyj Vestnik. Organ vserossijskogo soveta professional'nych sojuzov, 1918, Heft 3-4, S. 10-12, S. 12.

82 Z. Lilina: Soldaty Tyla. Ženskij trud vo vremja i posle vojny, Petrograd 1918, S. 36, 44.

83 L'vova: Ženščina-Rabotnica, S. 5; Lilina: Soldaty Tyla, S. 57; Bonwetsch: Die russische Revolution 1917, S. 106; Gaudin: Circulation and Production of News and Rumor, S. 63-64.

84 Zur Rolle von Sexualität in der vorrevolutionären, russischen Gesellschaft siehe: Laura Engelstein: The Key to Happiness. Sex and the Search for Modernity in Fin-de-Siècle Russia, Ithaca 1992; Olga Matich: Erotic Utopia. The Decadent Imagination in Russia's Fin de Siècle, Madison 2005 .

85 In Großbritannien hielten gesetzliche Regelungen fest, dass Frauen nach Ende des Kriegs Männer nicht länger in Fabriken ersetzen dürften - so groß war die Angst vor dem Aufbrechen klassischer Rollenbilder. Griffiths: Women's Factory Work, S. 21. 
des Zarenreichs oder der Stärke der Verbündeten. ${ }^{86}$ Sie konstruierten ein patriotisches Narrativ, das den Betrachter ebenfalls motivieren sollte, seinen eigenen Beitrag für den Sieg des Vaterlands zu leisten.$^{87}$ Obwohl die Fotografien Portraits der Arbeiterinnen präsentierten, traten die Frauen nie als Individuen mit einer persönlichen Geschichte in Erscheinung. Der Leser erfuhr weder Namen, noch in welcher Fabrik sie arbeiteten. Vielmehr entwickelten die Aufnahmen einen Prototyp der Arbeiterin einer Waffenfabrik, sozusagen ein universales Portrait einer Werktätigen. ${ }^{88}$ Es fungierte als Vorbild und ordnete sich in die Reihe der klassischen Helden - Krankenschwestern und Soldaten - ein. ${ }^{89}$ Damit fügten sich die Fotografien gut in die heroische Darstellung des Zarenreichs ein, wie sie in der Populärkultur des Ersten Weltkriegs verbreitet war. ${ }^{90}$

\subsection{Kaiserlicher Besuch in Fabriken}

Bis zum Ersten Weltkrieg war die Industrie kaum Repräsentationsplattform für die Zaren. Ihre Firmenbesuche wurden weder auf Gemälden noch

86 Beispielsweise: o. A.: U našich druzej i sojuznikov-francuzov, S. 12.

87 Neben dem Engagement der Arbeiterinnen und Krankenschwestern entwickelten sich auch philantropische Veranstaltungen zu beliebten patriotischen Ritualen. Hier war die Schwelle, sich für das Vaterland zu engagieren, noch niedriger als in den anfangs genannten Bereichen. Vladimir P. Buldakov: Mass Culture and the Culture of the Masses in Russia, 1914-22, in: Murray Frame u. a. (Hrsg.): Russian Culture in War and Revolution, 1914-22. Book 1. Popular Culture, the Arts and Institutions, Bloomington 2014, S. 25-52, S. 36 .

88 Es wäre aufschlussreich, einen Vergleich zwischen den Portraits und Fotografien der Arbeiterinnen und den Darstellungen „Mütterchen Russlands“ anzustellen. Möglicherweise lassen sich hier Parallelen aufdecken. Zum Motiv „Mütterchen Russland“ im Ersten Weltkrieg siehe: Oleg V. Riabov: The Symbol of „Mother Russia“ across the Epochs. From the First World War to the Civil War, in: Murray Frame u. a. (Hrsg.): Russian Culture in War and Revolution, 1914-22. Book 2. Political Culture, Identities, Mentalities, and Memory, Bloomington 2014, S. 73-97.

89 Stolarski: The Rise of Photojournalism, S. 186-187. Zum russischen Heldenmythos seit 1812 und dessen Krise während des Ersten Weltkriegs: Dietmar Neutatz; Reinhard Nachtigall: Helden als Fokus der Selbstverständigung von Gemeinschaft, in: Jahrbücher für Geschichte Osteuropas, Jg. 63/2015, Heft 4, S. 529-544, S. 538-539.

90 Richard Stites: Days and Nights in Wartime Russia. Cultural Life, 1914-1917, in: Aviel Roshwald; ders. (Hrsg.): European Culture in the Great War. The Arts, Entertainment, and Propaganda, 1914-1918, Cambridge 1999, S. 8-31, S. 23-25; Stolarski: Press Photography in Russia's Great War, S. 149. Zu russischen Illustrierten im Ersten Weltkrieg allgemein: Hubertus Jahn: Patriotic Culture in Russia during World War I, Ithaca 1995, S. 31-38. 
auf Fotografien festgehalten. ${ }^{91}$ Im Folgenden wird untersucht, welche Veränderungen das Verhältnis von Zar und Fabriken nach der Kriegserklärung durch das Deutsche Reich am 1. August 1914 durchlief; ob und wie Nikolaus II. Industriefotografien für seine Selbstinszenierung nutzte und welche visuellen Narrative er hierbei einsetzte. Zunächst wird kurz die Situation vor 1914 dargestellt, bevor der Text vertiefend auf die Kriegsjahre eingeht. Schließlich wird untersucht, auf welche Weise Fabrikanten sich die Besuche des Staatsoberhaupts zunutze machten.

Eine zentrale Quelle dieses Teilkapitels ist die vierbändige Publikation des russischen Generals Dmitrij Nikolaevič Dubenskij (1857-1923) ${ }^{92}$ Ego Imperatorskoe Veličestvo gosudar' imperator Nikolaj Aleksandrovič v dejstvujuččej armii $^{93}$ (Seine kaiserliche Hoheit Monarch Zar Nikolaus Alexandrovič im Einsatz der Armee). Dubenskij berichtet über die Reisen, die Nikolaus II. zwischen September 1914 und Februar 1916 im Russischen Reich unternahm. Gegenstand der Untersuchung sind darüber hinaus zwei Fotoalben, die Firmen in Auftrag gaben, um an den Besuch des Zaren in ihrem Unternehmen zu erinnern. Außerdem ergänzen lose Einzelaufnahmen vom Besuch des Zaren in der Maschinenfabrik in Brjansk die Studien. Neben den visuellen Dokumenten liefern die Tagebuchaufzeichnungen Nikolaus II. aus den Kriegsjahren zusätzliche Informationen.

91 In Frankreich existieren beispielsweise Gemäldevon Fabrikbesuchen Napoleons I. Pierrot: Les images de l'industrie en France, Abb. 93. Für das Zarenreich konnten trotz gezielter Recherchen in unterschiedlichen Archiven und Firmenmuseen keine entsprechenden Fotografien ausfindig gemacht werden. Eine Ausnahme bildet eine Fotografie des Besuchs Alexsanders III. in der Raffinerie der Brüder Nobel' in Baku am 9. Oktober 1888. Allerdings handelt es sich um Rohstoffförderung und nicht um verarbeitende Industrie. BDA Nicolas Oleinikoff Collection: A. Sjören: Yver ofver Anläggningar Tillhörande Naftaproduktions Bolaget Bröderna Nobel, o. O. 1888-189o, S. 28. Bei der Interpretation dieser Fotografie muss die herausragende Stellung des Unternehmens Nobel in Betracht gezogen werden und möglicherweise auch der Tod Ludwig Nobels (1831-1888) am 12. April 1888 in Cannes. Tolf: The Russian Rockefellers, S. 110, 182.

92 Dmitrij Nikolaevič Dubenskij wurde 1880 Offizier, diente in der Armee, betätigte sich jedoch ab 1900 als Herausgeber. Ab 1900 publizierte er die russische Zeitschrift Russkoe čtenie (Russische Lektüre), während des Russisch-Japanischen Kriegs gab er die Illustrierte Letopis'vojny sJaponiej (Chronik des Kriegs gegen Japan) heraus. Außerdem publizierte er populäre Bücher und Illustrationen. A. N. Apuchtin u. a. (Hrsg.): Voennaja ėnciklopedija, Bd. 9. Stichwort: Dubenskij N. D., Sankt-Peterburg, Moskva 1912, S. 232.

93 Dmitrij Nikolaevič Dubenskij: Ego Imperatorskoe Veličestvo gosudar' imperator Nikolaj Aleksandrovič v dejstvujuščej armii, Bd. 1-3, Petrograd 1915; Dmitrij Nikolaevič Dubenskij: Ego Imperatorskoe Veličestvo gosudar' imperator Nikolaj Aleksandrovič v dejstvujuščej armii, Bd. 4, Petrograd 1916. 
Die Analysemethoden dieses Kapitels sind Vergleiche auf der Text- und Bildebene. Dabei werden innerhalb der Publikation Dubenskijs sowohl die Text- und Bildnarrativ analysiert als auch die abgedruckten Fotografien von Fabrikbesuchen mit denjenigen Abzügen verglichen, die sich im Rossijskij gosudarstvennyj archiv kino foto dokumetov (Russisches Staatsarchiv für Film und Fotografie) befinden. Nur ein kleiner Teil der Aufnahmen von 1915 erschien letztlich in Dubenskijs Veröffentlichung, und gerade die nicht veröffentlichten Bilder geben Hinweise darauf, welches Narrativ der Autor verfolgte beziehungsweise welche davon abweichenden Narrative möglich gewesen wären. Schließlich werden die Text- und Bildinhalte der beiden Erinnerungsalben untersucht und mit den Bänden Dubenskijs verglichen, um die Interessen der unterschiedlichen Herausgeber auszumachen und herauszuarbeiten, wie sie sich der Person des Zaren bedienten.

\subsection{Zar und Fabrik - keine große Liebe}

Besuche russischer Monarchen in Unternehmen, besonders in Staatsbetrieben, hatten eine lange Tradition. Bei Peter dem Großen fielen zahlreiche Besuche mit der Gründung erster staatlicher Fabriken zusammen. ${ }^{94}$ Katharina die Große unternahm ebenfalls zahlreiche Herrscherreisen und besuchte unter anderen den Tul'skij oružejnyj zavod (Tulaer Waffenfabrik) ${ }^{95}$ sowie die Werft der Ižorsker Betriebe. ${ }^{96}$ Die Zarin verschaffte sich persönlich einen Eindruck von der Leistungsfähigkeit der Betriebe. Von diesen Besuchen wie auch von denen ihrer Nachfolger zeugen heute noch Schreiben an die Belegschaft oder Firmenleitung sowie unterschiedliche Geschenke der Monarchen. ${ }^{97}$ Seit dem Ende der Herrschaft Nikolaus I. wäre es technisch möglich gewesen, fotografische Aufnahmen zur Erinnerung an den kaiserlichen Gast anzufertigen. Dennoch fehlen im russischen Kontext solche Aufnahmen und dies gilt bis in die Regierungszeit Nikolaus II. hinein. ${ }^{98}$

94 Insofern kann streng genommen noch nicht von Fabrikbesuchen gesprochen werden, denn die Betriebe existierten noch nicht. Vielmehr initiierten die Besuche das Entstehen zukünftiger Fabriken.

95 Zybin: Istorija Tul'skago Imperatora Petra Velikago oružejnago zavoda, S. 134-135; Zybin: Kratkaja istorija Tul'skago Imperatora Petra Velikago oružejnago zavoda, S. 20-21.

96 Burim; Efimova: Ižorskie zavody, S. 8.

97 Siehe: Kapitel „Inszenierte Geschichte - Firmenjubiläen“, S. 179-240.

98 Eine Ausnahme bildet möglicherweise eine Fotografie aus dem Daimler-Archiv. Sie entstand 1903 und zeigt Nikolaus II., dem der Ingenieur Boris Loutzky einen Daimler-Lastwagen aus deutscher Produktion präsentierte. Im selben Jahr nahm die Firma Lessner in St. Petersburg die Produktion dieses Modells auf. Allerdings ist unklar, 
In dieser Hinsicht unterschied sich das Verhältnis zwischen Industriellen und dem russischen Staatsoberhaupt stark von der Situation im Deutschen Reich. Speziell die Industriellenfamilie Krupp pflegte eine enge Beziehung zum Kaiserhaus, und sowohl Wilhelm I. (1797-1888) als auch Wilhelm II. besuchten das Unternehmen in Essen regelmäßig. ${ }^{99}$ Bereits im Jahr 1861 hielt der Werksfotograf den Rundgang Wilhelms I. über das Fabrikgelände fest. ${ }^{100}$ Die Qualität dieser Aufnahme war eher gering, weswegen die Firmenleitung zu Werbezwecken einen fiktiven Stich in Auftrag gab, der den Besuch des Kaisers beim Dampfhammer zeigt. ${ }^{101}$ Solche Darstellungen wären auch für das Zarenreich denkbar und rein technisch problemlos anzufertigen gewesen. Man sucht sie jedoch vergeblich. Bei Krupp dokumentieren zahlreiche Gruppenfotografien in Alben offizielle Besuche deutscher Kaiser, Staatsoberhäupter und bekannter Persönlichkeiten wie 1909 den Besuch des Großfürsten Sergej Michajlovič Romanov (1869-1918). ${ }^{102}$ Zwar finden sich in russischen Firmenarchiven und Museen ebenfalls Gruppenaufnahmen, die Firmenbesuche dokumentieren, ${ }^{103}$ aber bis 1914 zeigt keine Aufnahme in diesem Kontext einen russischen Zaren. Es ist davon auszugehen, dass Industrielle nicht abgeneigt gewesen wären, entsprechende Fotografien für Reklamezwecke zu gebrauchen. Für diese Annahme spricht das Verhalten der Firmenleitungen bei Firmenjubiläen: Wenn Telegramme von Mitgliedern der Familie Romanov eingingen, war dies ein willkommener Anlass, um an Lokalredaktionen mit der Bitte heranzutreten,

ob es sich hier um einen Besuch des Zaren beim entsprechenden Betrieb handelte oder ob Loutzky zum Monarchen gekommen war. Entscheidend ist, dass in der russischen Presse solche Aufnahmen vor dem Ersten Weltkrieg nicht erschienen. Die Allgemeine Automobilzeitung, Wien 1903, Nr. 26 druckte die Fotografie; im Daimler-Archiv: ArchivNummer 1007 DIG2110.

99 Diese Besuche nutzte das Unternehmen, um seine besondere Nähe zum Herrscherhaus werbewirksam zu präsentieren, und die Monarchen demonstrierten mit den Aufnahmen von Waffen und Maschinen die Leistungsfähigkeit der deutschen Industrie. Hartmut Pogge von Strandmann: Krupp in der Politik, in: Klaus Tenfelde (Hrsg.): Bilder von Krupp. Fotografie und Geschichte im Industriezeitalter, München 1994, S. 181-201, S. 182.

100 Ralf Stremmel: Gruppenbilder. Die Krupps und ihre Netzwerke, in: Alfried Krupp von Bohlen und Halbach-Stiftung (Hrsg.): Krupp. Fotografien aus zwei Jahrhunderten, Berlin, München 2011, S. 171-172, S. 171.

101 Hannig: Fotografie als historische Quelle, S. 284.

102 HAK: WA 16 e 89. Bossen: Eine gemeinsame Geschichte erschaffen, S. 46-47; Herz: Gesammelte Fotografie und fotografierte Erinnerungen, S. 263, 265; Pogge von Strandmann: Krupp in der Politik, S. 185-194.

103 Siehe hierzu beispielsweise mehrere unsystematische Einzelfotografien in den Beständen des Museums des Putilovskij zavod. 
das Schreiben abzudrucken. ${ }^{104}$ Fotografien des Zaren wären mit großer Wahrscheinlichkeit in der Presse oder auf Postkarten erschienen.

Das Fehlen entsprechender Bilder lässt sich nicht darauf zurückführen, dass die Zaren die Fotografie als Medium generelle ablehnten. Insbesondere Nikolaus II. fotografierte selbst gerne ${ }^{105}$ und förderte beispielsweise das monumentale Projekt einer fotografischen Dokumentation des Zarenreichs, das Prokudin-Gorskij in den Jahren vor dem Ersten Weltkrieg vorantrieb. ${ }^{106}$ Auch ließ der letzte Zar sich durchaus mit Symbolen der technischen und gesellschaftlichen Veränderungen ablichten, so in Zusammenhang mit der Eisenbahn. ${ }^{107}$ Hingegen lehnte Nikolaus II. es offensichtlich ab, sich in einem industriellen Kontext von Fabiken zu inszenieren. Fotografien aus Werkstätten oder vor Maschinen entsprachen nicht der von ihm gewünschten Zarendarstellung. Wie Richard Wortman herausgearbeitet hat, betonte der letzte Romanov auf dem Thron besonders die Einheit zwischen Zar und russischem Volk. ${ }^{108}$ Die Nähe zur Bevölkerung inszenierten Aufnahmen, die den Zaren bei offiziellen Anlässen und Truppenbesuchen zeigten, beispielsweise bei der Visite des Infanterieregiments aus Jasnaja Poljana, dessen Mitglieder sich überwiegend aus Bauern rekrutierten. Außerdem vermittelten Bilder aus dem Privatleben der Zarenfamilie den Eindruck einer bürgerlichen Bilderbuchfamilie und reduzierten dadurch - zumindest imaginär - den Unterschied zwischen den Herrschern und der Bevölkerung. Ab der Jahrhundertwende

104 GAVMF f. 417, op. 2, d. 687, l. 12. Siehe auch: Kapitel „Inszenierte Geschichte - Firmenjubiläen“, S. 179-240.

105 Wortman: Scenarios of Power, Bd. 2, S. 494.

106 Siehe hierzu insbsondere das Dissertationsprojekt von Henning Lautenschläger: Immortalising Russia in an Age of Revolution? - Sergej Prokudin-Gorskijs Farbfotografien vom Zarenreich bis zur Pariser Emigration (ca. 1906-1948).

1071891 ließ sich der damalige Thronfolger fotografieren, während er die Baustelle der Transsibirischen Eisenbahn eröffnete. RNB: Ė AlT10o/4-1/2: Sibirskaja Železnaja Doroga (do 1917 g.): Otkrytie cesarevičem postrojki Velikoj Sibirskoj ž. d., Vladivostok 1891, S. 6-7. Zu diesem Ereignis auch: Schenk: Russlands Fahrt in die Moderne, S. 26o-261. Schenk zufolge wurden in Diskussionen über die Eisenbahn im Zarenreich dem neuen Verkehrmittel imperiale und zivilisatorische Kräfte zugeschrieben. Aspekte, die in den Auseinandersetzungen zu Fabriken fehlten. Dies könnte ein Grund gewesen sein, warum Nikolaus II. sich entsprechend anders verhielt.

108 Damit folgte Nikolaus II. dem Vorbild seines Vaters und Großvaters. Allerdings misstraute Nikolaus II. so gut wie allen Institutionen. Infolge dessen verzichtete er in seiner Selbstinszenierung auf die vermittelnde Rolle beispielweise der orthodoxen Kirche und präsentierte eine unmittelbare Beziehung zwischen dem Herrscher und den Untertanen. Wortman: Scenarios of Power, Bd. 2, S. 322, 366. 
zeigte sich der Monarch immer wieder bei Gesprächen mit der Bevölkerung. ${ }^{109}$ Er verstärkte dadurch das Narrativ der engen und gottgewollten Verbindung von Zar und Volk. Bis zum Ersten Weltkrieg bestand das russische Volk in diesen Darstellungen überwiegend aus Bauern, die der Monarch besuchte und um deren Sorgen er sich kümmerte. Mit dieser Volksnähe bewegte sich Nikolaus II. ganz im Trend der Herrscherrepräsentation anderer europäischer Monarchen. ${ }^{110}$ Er stieß mit diesem Verhalten aber die traditionellen Eliten des Zarenreichs vor den Kopf. ${ }^{111}$ Auch den Industriellen billigte er kaum Platz in seiner öffentlichen Selbstrepräsentation zu. ${ }^{112}$ Fabrikarbeiter traten in der Inszenierung des Zaren an keiner Stelle auf.

\subsection{Zar und Arbeiter}

Obwohl die Bedeutung der russischen Industrie seit 1890 stetig zunahm, lehnte Nikolaus II. es ab, diesen Bereich der Ökonomie durch seine Präsenz zu adeln und auf diese Weise zu fördern. Unter den Mitgliedern der russischen Eliten war die Angst vor einer revolutionären Arbeiterschaft verbreitet, welche den Fortbestand des Zarenreichs gefährden könnte. ${ }^{113}$ Aber die Elite war nicht in der Lage, die Herausbildung einer russischen Arbeiterbewegung zu verhindern. Nachdem um 1900 das starke Wirtschaftswachstum der 1880er und 189oer Jahre eingebrochen war, kam es $1903 \mathrm{zu}$ einer Streikwelle in den russischen Industriezentren. Auch die Revolutionsjahre waren durch viele Streiks und Arbeitskämpfe geprägt. ${ }^{114} 1909$ verbesserte sich die Wirtschaftslage, doch bereits 1913 zeichnete sich eine neue Welle der Proteste ab, und in der ersten Hälfte des Jahres 1914 verzeichneten offizielle Stellen eine Vielzahl

109 Stolarski: The Rise of Photojournalism, S. 65-67.

110 Wortman: Scenarios of Power, Bd. 2, S. 490-497. Zum British Empire siehe auch: Thomas Richards: The Commodity Culture of Victorian England. Advertising and Spectacle, 18511914, Stanford 1990, S. 102-103.

111 Alexander III. hatte in seiner Selbstpräsentation die Beziehung des Zaren zu den Eliten der russischen Gesellschaft besonders betont. Mit dieser Darstellung brach Nikolaus II. Wortman: Scenarios of Power, Bd. 2, S. 501.

1121913 beim 300. Jahrestag der Romanov-Dynastie waren die Industriellen unter den geladenen Gästen unterrepräsentiert. Die Kaufleute des Moskauer Börsenkommitees bestanden jedoch darauf, dem Zaren im ersten Saal des Kremls ihre Aufwartung zu machen. Nachdem dies zunächst nicht vorgesehen war, akzeptierte Nikolaus II. diesen Wunsch. Heller: Auf dem Weg zum Bourgeois?, S. 56; Rolf: Das sowjetische Massenfest, S. 40.

113 Blackwell: The Beginnings of Russian Industrialization, S. 142; Kelly; Smith: Commercial Culture and Consumerism, S. 130.

114 Neutatz: Träume und Alpträume, S. 103; Grant: Big Business in Russia, S. 80-82. 
an Streiks in russischen Fabriken, ${ }^{115}$ fast so viele wie im gesamten Jahr $1905 \cdot{ }^{116}$ Im Juli 1914 bauten Arbeiter in St. Petersburg beim Generalstreik gar aus umgeworfenen Straßenbahnen Barrikaden und setzten sich gegen Polizei und Militär zu Wehr. ${ }^{117}$

Der sich bereits abzeichnende Krieg gab den Protesten einen neuen Stellenwert, denn es beteiligten sich besonders viele Arbeiter aus metallverarbeitenden Fabriken. Sie stellten kriegswichtige Waffen und Ausrüstungsgegenstände her. Die Streiks stellten somit nicht nur eine Bedrohung der inneren Sicherheit dar, sondern konnten im Kriegsfall auch die Schlagkraft der russischen Armee maßgeblich beeinträchtigen. Entsprechend war die russische Regierung darum bemüht, an der Heimatfront Ruhe sicherzustellen.

Ähnlich wie in Deutschland, Frankreich oder Großbritannien führte der Kriegsausbruch im Zarenreich zu einer temporären Beilegung der Konflikte zwischen unterschiedlichen politischen und gesellschaftlichen Gruppen. ${ }^{118}$ Bis zum Frühsommer 1915 kam es in Russland zu keinen weiteren Streiks. ${ }^{119}$ Trotz der vorübergehenden Einigung setzte Nikolaus II. alles daran, die Menschen hinter sich zu scharen und zu mobilisieren, um den inneren Frieden zu sichern. ${ }^{120}$ So begann er nach Kriegsbeginn, sein Image zu modifizieren, und nahm an zahlreichen staatlichen und kirchlichen Zeremonien teil. ${ }^{121}$ Außerdem reiste der Zar ab September 1914 durch das Russische Reich

115 Gerade in St. Petersburg beteiligte sich laut Presseberichten mehr als ein Drittel, Polizeiberichten zufolge fast ein Viertel der Bevölkerung an den Streiks. Ingold: Der große Bruch, S. 51 .

116 Dowler: Russia in 1913, S. 272; D. C. B. Lieven: Russia and the Origins of the First World War, London 1983, S. 18-19; Robert B. McKean: St. Petersburg between the Revolutions. Workers and Revolutionaries, June 1907-February 1917, New Haven 1990, S. 297-317.

117 Wortman: Scenarios of Power, Bd. 2, S. 507.

118 Antoine Prost: Workers, in: Jay Winter; Charles Stille (Hrsg.): The Cambridge History of the First World War, Bd. 2. The State, Cambridge 2014, S. 325-357, S. 349-355.

119 Hildermeier: Die Russische Revolution, S. 122. Allerdings nahm ab Mitte 1915 die Anzahl der Streiks im Zarenreich wieder stark zu. Jurij I. Kir’janov: Rabočie Rossii i vojna. Novye podchody k analizu problemy, in: Vladimir L. Mal'kov (Hrsg.): Pervaja mirovaja vojna. Prolog XX veka, Moskva 1998, S. 432-445, S. 435-436.

120 Vergleichbare Initiativen unternahmen auch andere europäische Monarchen. Boris Kolonitskii: Russian Leaders of the Great War and Revolutionary Era in Representations and Rumors, in: Murray Frame u. a. (Hrsg.): Russian Culture in War and Revolution, 1914-22. Book 2. Political Culture, Identities, Mentalities, and Memory, Bloomington 2014, S. $17-54$, S. 29.

121 Boris Kolonickij: Tragičeskaja ėrotika. Obrazy imperatorskoj sem’i v gody Pervoj mirovoj vojny, Moskva 2010, S. 90. 
und besuchte verschiedene militärische Einheiten, Hospitäler sowie neun Fabriken und Werften. ${ }^{122}$

General Dubenskij berichtete in einer vierbändigen Publikation über diese Reisetätigkeiten des Staatsoberhaupts und veranschaulichte in Texten und Bilder, wie sehr sich Nikolaus II. um seine Bevölkerung bemühte. Damit passten die Bände zu anderen patriotischen Veröffentlichungen, die gerade während des ersten Kriegsjahrs im Zarenreich in großer Zahl erschienen. ${ }^{123}$ Am Zarenhof galten die Reiseberichte als eines der wichtigsten Propagandamittel zur Mobilisierung der Bevölkerung. ${ }^{124}$ In Petrograd und Moskau waren die Bände für einen Preis von 6o Kopeken (Band 1) bis 1,20 Rubel (Band 2, 3, 4) in ausgesuchten Buchläden sowie an den Kiosken der Eisenbahn im Angebot. ${ }^{125}$ Dem Autor zufolge waren die Bemühungen von Erfolg gekrönt, denn 1915 schrieb Dubenskij, dass dank der Publikationen das Bild des Zaren deutlich präsenter sei und die Bevölkerung hinter ihm stünde. ${ }^{126}$ Inwieweit diese Einschätzung der Realität entsprach, ist jedoch fraglich. Bereits im Sommer 1915 nahm die Kritik an Nikolaus II. zu, weite Teile der russischen Bevölkerung begegneten dem Monarch gar mit großem Misstrauen. ${ }^{127}$ Offenbar glaubten Nikolaus II. und seine Vertrauten jedoch an die versöhnliche Wirkung der Publikation, denn 1916 erschien ein weiterer Band der Reihe.

Inhaltlich orientiert sich General Dubenskij am Krönungsalbum Nikolaus II. und an der 1913 erschienenen Zarenbiographie von Major-General Andrej Georgievič El'čaninov (1868-1918).128 Das zentrale Narrativ der Biografie präsentiert den Zaren als Vater, der sich aufopfernd um die Menschen kümmert - eine Darstellung, die Dubenskij adaptierte. Vor dem Hintergrund des Kriegs erweiterte er jedoch das ,russische Volk': 1915 gehörten ihm erstmals

122 Nikolaus II. stattete folgenden Unternehmen Besuche ab: Oružejnyj Petra Velikago zavod am 21.11.1914 in Tula; Brjanskij Aleksandrovskij Južno-Rossijskij zavod am 31.01.1915 in Ekaterinoslav; Putilovskij zavod am 31.03.1915 in Petrograd; unterschiedliche Werften in Nikolaevsk am 15.04.1915; Brjanskie zavody am 20.04.1915 in Brjansk; Baltijskij zavod am 09.06.1915 in Petrograd; Admiralitejskij sudostroitel'nyj zavod am 18.07.1915 in Petrograd; Russko-Baltijski zavod am 28.10.1015 in Revel'; Farforovyj i Steklanyj zavod am 01.12.1915 in Petrograd.

123 Hubertus Jahn: For Tsar and Fatherland? Russian Popular Culture and the First World War, in: Stephen Frank; Mark Steinberg (Hrsg.): Cultures in Flux. Lower-Class Values, Practices, and Resistance in Late Imperial Russia, Princeton 1994, S. 131-146, S. 144.

124 Kolonickij: Tragičeskaja ėrotika, S. 99.

125 Dubenskij: Ego Imperatorskoe Veličestvo, Bd. 4, S. 237.

126 Dubenskij: Ego Imperatorskoe Veličestvo, Bd. 3, S. 3-4.

127 Kolonickij: Tragičeskaja èrotika, S. 150-151, 194-195, 205-207, 219, 235; Michael Cherniavsky: Tsar and People. Studies in Russian Myths, New Haven, London 1961, S. 221.

128 Wortman: Scenarios of Power, Bd. 2, S. 346, 489-490. 
auch Arbeiter an. Die Fotografien für die Berichte über die Zarenreisen fertigte Aleksandr Karlovič Jagel'skij (unbekannt-1916) an. ${ }^{129}$ Er war einer der Inhaber des Fotoatelier K. E. fon Gan i Ko (K. E. von Hahn und Co) in Carskoe Zelo und ein Vertrauter der Zarenfamilie. Bereits ab den 189oer Jahren erhielt das Atelier zahlreiche Aufträge, Fotografien des Monarchen und seiner Familie anzufertigen. Jagel'skij brachte den Kindern Nikolaus II. das Fotografieren bei, und im Jahr 1911 erhielt er den Titel Fotograf Ego Veličestva (Fotograf seiner Hoheit). In Dubenskijs Veröffentlichung ergänzen Portraits und Zeichnungen der Künstler Michail Viktorovič Rundal'cev (1871-1935) und Perikl Spiridonovič Ksidias (1872-1942) Jagel'skij Aufnahmen.

Um die Narrative und die visuelle Argumentation Jagel'skij und Dubenskijs nachzuvollziehen, eignet sich der Bericht über den Aufenthalt Nikolaus II. in der Maschinenfabrik in Brjansk besonders gut. Die Schilderung umfasst neun Seiten und sieben Fotografien in variierenden Formaten. Sie zeigen die traditionelle Begrüßung des Zaren mit Brot und Salz durch zwei Bauern, das Begrüßungsspalier von Schülerinnen und Schülern sowie Aufnahmen vom Fabrikgelände und aus den Werkshallen. Im begleitenden Text schildert Dubenskij die Ankunft des Zaren, sein Treffen mit Vertretern der Zemstvo, den Rundgang durch die Produktionsanlagen und eine Industrieausstellung mit fabrikeigenen Exponaten sowie ein Treffen mit Arbeitern. Wie der Autor versichert, besichtigte der Zar ohne vorherige Absprache zwei Arbeiterwohnungen, ${ }^{130}$ wobei diese Schilderung starke Parallelen zu den früheren Besuchen bei russische Bauern aufweist. ${ }^{131}$

Dubenskij stellt zunächst das Unternehmen vor und beschreibt dann detailliert den Ablauf des Zarenbesuchs. Die sieben illustrierenden Fotografien folgen dabei nur teilweise dem Text. Sie konstruieren vielmehr eine parallel laufende Erzählung. Den Auftakt bilden die Begrüßungsszenen, in denen Nikolaus II. von zwei Bauern Brot und Salz überreicht bekommt, und das Spalier der Schülerinnen und Schüler, die den Monarchen willkommen heißen. Auf diese Bilder folgen fünf Aufnahmen des Zaren, abwechselnd in einer Fabrikhalle oder unter freiem Himmel. Bei genauem Betrachten fällt auf, dass mindestens zwei dieser Bilder denselben Ort zeigen, obwohl sie

129 Dubenskij: Ego Imperatorskoe Veličestvo, Bd. 3, S. 197. Zu Jagel'skij: Popov: Iz istorii rossijskoj fotografii, S. 164-166.

130 In wie weit dieser Besuch bei den Arbeitern wirklich spontan war, ist fraglich, denn Nikolaus II. tauschte der Schilderung zufolge mit den Bewohnern Geschenke aus - die er entsprechend im Voraus vorbereitet haben dürfte. Dubenskij: Ego Imperatorskoe Veličestvo, Bd. 3, S. 159-16o.

131 Hierzu beispielsweise Fotografien in folgenden Illustrierten: Iskry, 26.05.1913, S. 1; Iskry, 02.06.1913, S. 1; Ogonëk, 20.01.1913, S. 1. 
nicht hintereinander gedruckt sind. ${ }^{132}$ Der Herausgeber wollte das Gefühl vermitteln, dass der Zar umhergegangen sei und unterschiedliche Dinge angesehen habe.

Die gedruckten Fotografien ließ Dubenskij bearbeiten und zuschneiden, so dass sie den Zaren besser zur Geltung brachten. Der Herausgeber entfernte beispielsweise den leeren Vordergrund bei der Begrüßung des Zaren mit Salz und Brot, um den Bildaufbau symmetrisch zu gestalten und um die Menschengruppe mit Nikolaus II. besser in Szene zu setzen. ${ }^{133}$ Fast alle Aufnahmen zeigen den Monarchen in einer Position, die seine besondere Bedeutung unterstreicht: in der Bildmitte. ${ }^{134}$ War der Zar verdeckt oder nur sehr klein zu erkennen, stellte dies ein Ausschlusskriterium für den Herausgeber dar. ${ }^{135}$

Darüber hinaus wählte Dubenskij Fotografien aus, die seinem Narrativ des fürsorglichen Zaren entsprachen und die enge Verbindung von Zar und Volk, in diesem Fall den Arbeitern, illustrierten. Das Wort laskovo (zärtlich, liebevoll), mit dem der Autor die Art und Weise beschreibt, wie der Zar sich nach dem Leben der Arbeiter erkundigte, unterstreicht, wie aufopferungsvoll sich Nikolaus II. um die einfachen Menschen bemühte. ${ }^{136}$ Folglich sortierte Dubenskij diejenigen Fotografien aus, die den Zaren allein, mit Mitgliedern seines Besuchskomitees oder mit der Fabrikleitung abbildeten. ${ }^{137}$ Nur Aufnahmen, die den Zaren zusammen mit Arbeitern zeigten, entsprachen Dubenskijs Vorstellungen. Abbildung 78 stellt eine ideale Illustration des fürsorglichen Zaren dar.

Dennoch wählte Dubenskij sie nicht für seine Veröffentlichung aus. Verantwortlich dafür war wohl der Mann, der auf der linken Seite direkt in die Kamera blickt (Abb. 78a). Seine Körpersprache und Kopfdrehung legen nicht nur die Präsenz des Fotografen offen, sondern der direkte Blickkontakt zieht außerdem die Aufmerksamkeit des Betrachters auf sich und lenkt dadurch von Nikolaus II. ab.

Jagel'skij fertigte deutlich mehr Bilder an, als letztlich in der Publikation erschienen. Im Fall des Zarenbesuchs in Brjansk zeigten besonders viele

132 Dubenskij: Ego Imperatorskoe Veličestvo, Bd. 3, S. 159, 161. Nicht ganz klar ist, ob auch die Innenansichten aus derselben Werkshalle stammten. Wenn es zwei unterschiedliche Hallen waren, fand zumindest in beiden eine Ausstellung statt, was die großen Schilder im Hintergrund zeigen. Dubenskij: Ego Imperatorskoe Veličestvo, Bd. 3, S. 158, 160.

133 Dubenskij: Ego Imperatorskoe Veličestvo, Bd. 3, S. 155.

134 Um dies zu erreichen, beschnitt Dubenskij teilweise auch die Vorlagen. RGAKFD: 5-7502; 5-7495; zum vergleich Dubenskij: Ego Imperatorskoe Veličestvo, Bd. 3, S. 161, 162.

135 RGAKFD: 5-3927; 5-7500; 5-7496; GARF f. 601, op. 1, d. 1675, l. 2, 8.

136 Dubenskij: Ego Imperatorskoe Veličestvo, Bd. 3, S. 159.

137 RGAKFD: 5-7501; 5-7503, 5-1048; GARF f. 601, op. 1, d. 1675, l. 22. 


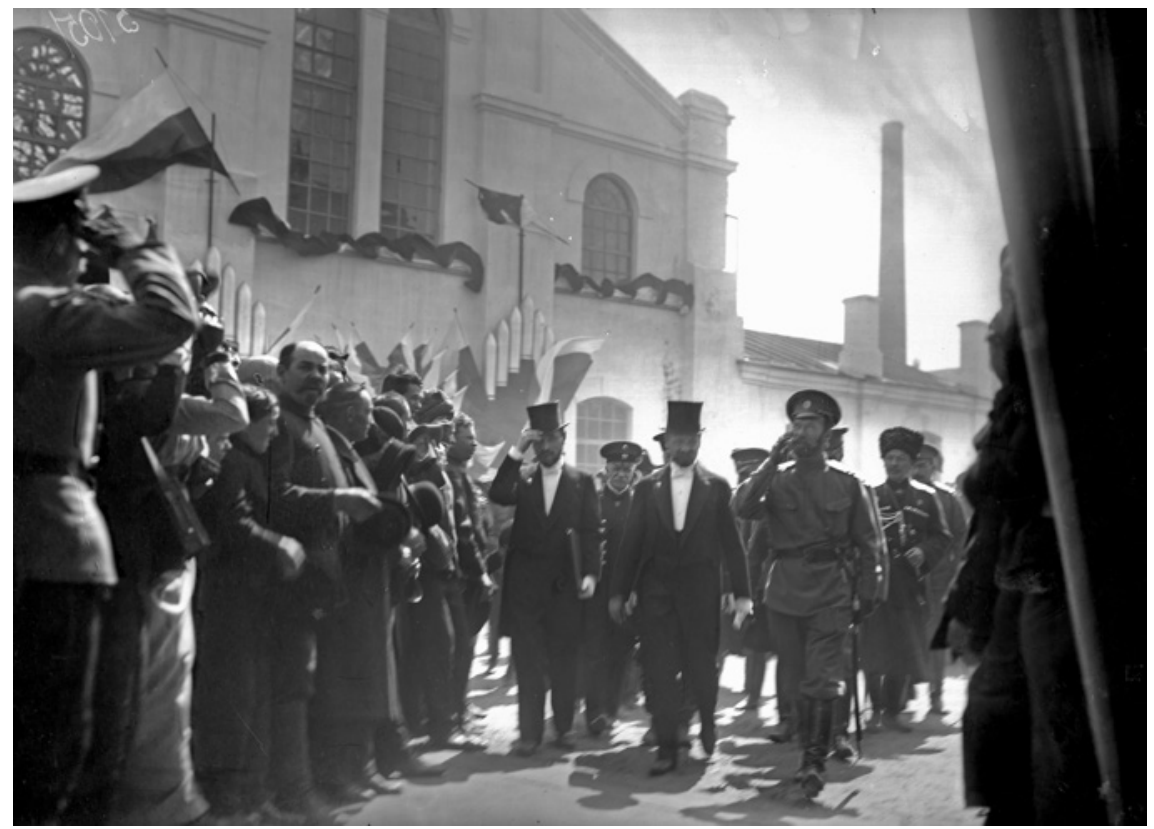

Abb. 78 Aleksandr Karlovič Jagel'skij: Besuch des Zaren Nikolaj II. im Brjansker Betrieb in Bežic. Zar Nikolaj II. besichtigt mit Gefolge das Betriebsgelände (Poseščenie Imperatorom Nikolaem II Brjanskogo zavoda v Bežice. Imperator Nikolaj II so svitoj prochodjat po territorii zavoda), Brjansk 1915. CGAKFD 5-1051 č/b, Indeks Z 010

Abb. $78 \mathrm{a}$

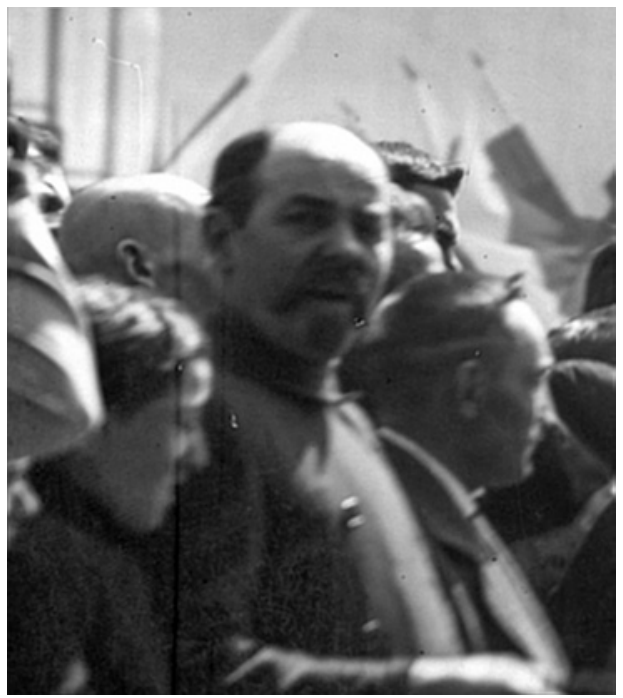




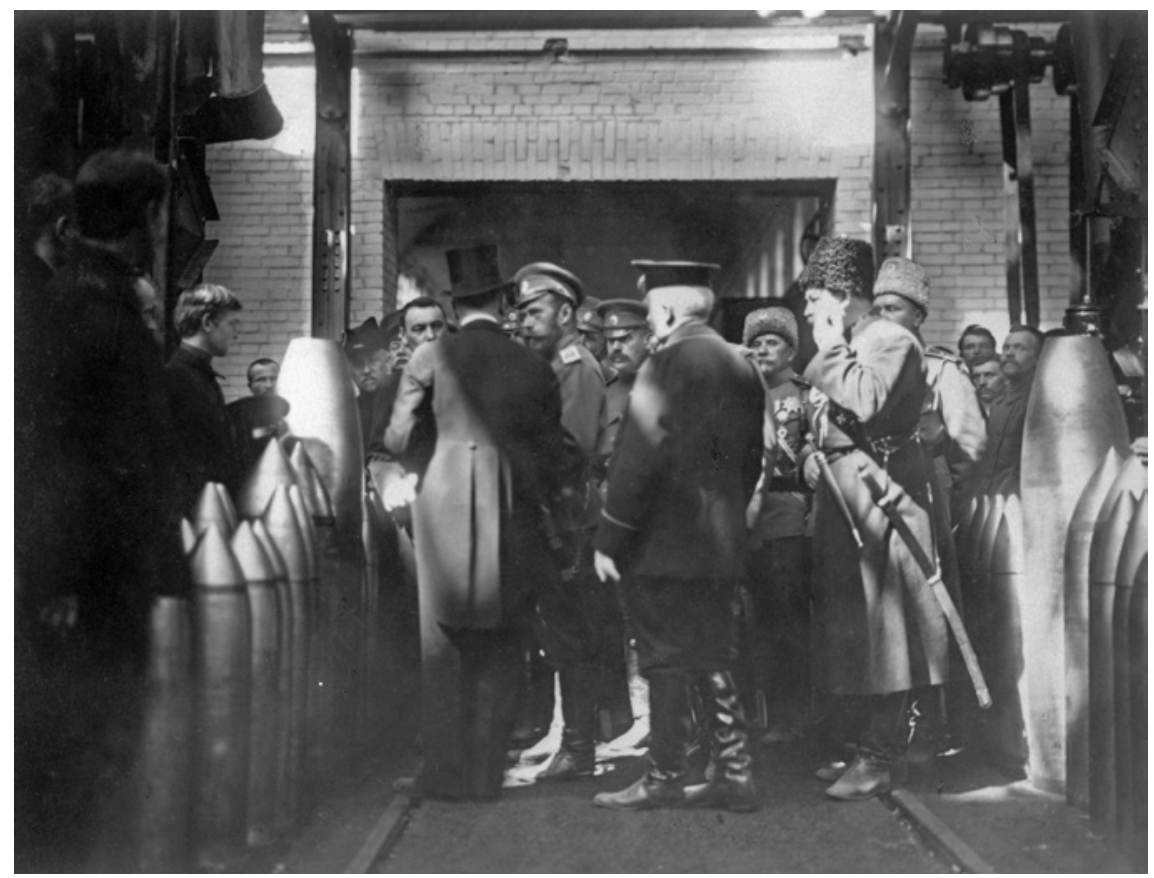

Abb. 79 Aleksandr Karlovič Jagel'skij: Zar Nikolaj II. mit Gefolge auf dem Betriebsgelände der Aktiengesellschaft Brjansker Betrieb (Imperator Nikolaj II so svitoj na territorii zavoda akcionernogo obščestva Brjanskij zavod), Brjansk 1915. CGAKFD $\mathrm{Al} 269$ sn 113

Aufnahmen die Besichtigung der Ausstellung und der Fabrikhallen. Dabei fällt eine Fotografie besonders auf (Abb. 79).

Im Vordergrund sind Nikolaus II. und Männer in Uniformen zu erkennen, von denen einer vermutlich mit dem Zaren spricht oder ihm etwas erklärt. Vom rechten und linken unteren Bildrand leitet ein Spalier unterschiedlich großer Geschützhülsen den Blick des Betrachters in die Mitte des Bildes auf den Monarchen und sein Entourage. In Gestalt der Granaten ist auf dieser Aufnahme die Zerstörungsmacht des Kriegs offensichtlich präsent. Das scheint in einem Betrieb, der zu den größten russischen Rüstungsbetrieben zählte, nicht verwunderlich. ${ }^{138}$ In Brjansk mangelte es nicht an Motiven für vergleichbare Fotografien. Umso mehr erstaunt, dass Jagel'skij in keiner Aufnahmen die lokale Waffenproduktion feierte. Dies hing zweifelsohne mit Dubenskijs

138 Gatrell: Russia's First World War, S. 24. 
Anweisungen oder den Wünschen Nikolaus II. zusammen, denn kein Bild zeigt den Zaren mit Kriegstechnik.139

Dubenskij klammerte die unmenschlichen Aspekte des Ersten Weltkriegs in allen vier Bänden aus. Wenn der Zar Lazarette besuchte, waren die Verwundeten immer ansehnlich zurechtgemacht, es waren ausschließlich Männer mit unversehrten Gesichtern zu sehen. ${ }^{140}$ Möglicherweise befürchtete der Zar, persönlich für das Leid der Verwundeten verantwortlich gemacht zu werden. Diese Befürchtung hatte einen guten Grund, denn nachdem Nikolaus II. sich im August 1915 zum obersten Feldherrn erklärt hatte, galt er persönlich als Verantwortlicher für militärische Niederlagen. ${ }^{141}$ Zudem könnte Dubenskij befürchtet haben, dass entsprechende Darstellungen die Kampfmoral der Soldaten negativ beeinflussen würde. ${ }^{142}$ In den vier Bänden waren weder das Kriegsgeschehen, noch die militärische Ausstattung oder gar der Gaskrieg Gegenstand der Inszenierungen, obwohl gerade im Ersten Weltkrieg die Kriegstechnik von entscheidender Bedeutung war. ${ }^{143}$ Statt Fotografien von Kanonen verweisen Aufnahmen vom Zaren an Kartentischen auf die Front und den Krieg. ${ }^{144}$ Nur eine Darstellung innerhalb der vier Bände zeigt Nikolaus II. bei der Inspektion eines Geschosses, das russische Soldaten

139 Auch auf Abbildung 78 sind an der Fassade Granaten zu erkennen. Dies könnte ein zusätzlicher Grund gewesen sein, diese Fotografie nicht zu publizieren.

140 Dubenskij: Ego Imperatorskoe Veličestvo, Bd. 1, S. 31, 33; Dubenskij: Ego Imperatorskoe Veličestvo, Bd. 2, S. 15; Dubenskij: Ego Imperatorskoe Veličestvo, Bd. 3, S. 13-15, 35, 193.

141 Stephen M. Norris: A War of Images. Russian Popular Prints, Wartime Culture, and National Identity, 1812-1945, DeKalb 2006, S. 161. Außerdem hatten seine Berater vergeblich versucht, Nikolaus II. zu verstehen zu geben, dass er bereits seit der Niederlage im Russisch-Japanischen Krieg als unglücklicher Zar galt, wie Kolonickij ausführt. Der Monarch weigerte sich jedoch, diesen Stimmen Gehör zu schenken. Kolonickij: Tragičeskaja ėrotika, S. 150-151; Kolonitskii: Russian Leaders of the Great War, S. 32.

142 Es war umstritten, ob entsprechende Bilder die Soldaten abhärteten oder Ablehnung und Befehlsverweigerung hervorriefen. Auf letztere Reaktion setzten besonders pazifistische Kreise, die ausgesprochen brutale Fotografien verbreiteten. John Kinder: Paying with Their Bodies. American War and the Problem of the Disabled Veteran, Chicago, London 2015, S. 231-232; Sabine Kienitz: Beschädigte Helden. Kriegsinvalidität und Körperbilder, 1914-1923, Paderborn 2008, S. 48; Stefanie Klamm: Bilder zerstörter und vermessener Körper. Medizin und Anthropologie im Ersten Weltkrieg, in: Ludger Drenthal; dies. (Hrsg.): Fotografie im Ersten Weltkrieg, Berlin 2014, S. 82-88; Ernst Piper: Nacht über Europa. Kulturgeschichte des Ersten Weltkriegs, Berlin 2013, S. 144-146.

143 Frédéric Guelton: Technology and Armaments, in: Jay Winter; Charles Stille (Hrsg.): The Cambridge History of the First World War, Bd. 2. The State, Cambridge 2014, S. 240-265, S. 245, 259-264. Zum Gaskrieg beispielsweise: Olivier Lepick: La grande guerre chimique, 1914-1918, Paris 1998.

144 Dubenskij: Ego Imperatorskoe Veličestvo, Bd. 1, S. 13; Dubenskij: Ego Imperatorskoe Veličestvo, Bd. 4, S. I. 
laut Bildunterschrift von den Deutschen erbeutet hatten. Hier repräsentiert die Fotografie des Geschützes einen Erfolg der russischen Armee, was die Darstellung legitimierte. ${ }^{145}$ Selbstverständlich war der Konflikt auch in den zahllosen Aufnahmen präsent, mit denen Jagel'skij die Truppenbesuche des Monarchen dokumentierte. Allein die große Anzahl an Soldaten verwies auf die militärischen Auseinandersetzungen. Dubenskij achtete jedoch streng darauf, immer einen Krieg mit ,menschlichem Antlitz‘ zu zeigen.

Nikolaus' Selbstinszenierung unterschied sich stark von der westeuropäischer Herrscher. Beispielsweise ließ sich 1916 der englische König George V. während eines Fabrikbesuchs in einem Arsenal zwischen unzähligen Granaten fotografieren. ${ }^{146}$ Das britische Beispiel demonstrierte die Schlagkraft und Ausstattung der englischen Armee. Auch für Wilhelm II. waren Fotografien vor Geschützen oder sonstigem militärischen Gerät Teil seiner Selbstinszenierung und dies nicht erst mit Beginn des Ersten Weltkriegs. ${ }^{147} \mathrm{Im}$ Gegensatz dazu war Nikolaus II. weniger daran gelegen, seinen Lesern die militärische Stärke der russischen Truppen zu präsentieren. Dubenskijs Veröffentlichungen hatten vielmehr das Ziel, das Bild eines friedliebenden Monarchen zu konstruieren: Der Vater des russischen Volkes bemüht sich um seine Kinder. Jeder Hinweis darauf, in welche unmenschlichen und zerstörerischen Kämpfe er seine Untergebenen schickte, klammerte die Propaganda aus. ${ }^{148}$

\subsection{In Erinnerung an den Monarchen}

Die vierbändige Beschreibung der Zarenreise war eine offizielle Propagandaschrift, die der Zar vor der Veröffentlichung abgesegnet hatte. Im Laufe des Ersten Weltkriegs verlor der Zarenhof jedoch die Kontrolle über die Darstellung des Monarchen und seiner Familie. Es erschienen an der Zensur vorbei zahlreiche Postkarten mit Fotografien der Herrscherfamilie. ${ }^{149}$ Auch Fabrikbesitzer nutzten den Besuch des Zaren und stellten diesen in einen für sie nützlichen Kontext. Inwieweit die Industriellen dazu die offizielle Genehmigung der Zensurbehörden einholten oder nach eigenem Gutdünken vorgingen, lässt sich heute nicht mehr nachvollziehen. Allerdings deutet einiges drauf hin,

\footnotetext{
145 Dubenskij: Ego Imperatorskoe Veličestvo, Bd. 1, S. 45.

146 IWM: HU 96427. Siehe hierzu: in diesem Kapitel S. 337-339.

147 Pogge von Strandmann: Krupp in der Politik, S. 195; Tenfelde: „Krupp bleibt doch Krupp“, S. $91-95$.

148 Erst im letzten Band zeigt eine Fotografie den Zaren, wie er die Waffen seiner Streitkräfte begutachtet. Dubenskij: Ego Imperatorskoe Veličestvo, Bd. 4, S. 127.

149 Kolonickij: Tragičeskaja èrotika, S. 92.
} 
dass die Unternehmen den Inhalt ihrer Erinnerungsalben nicht detailliert mit dem Zarenhof abstimmten: Die Narrative der Publikationen weichen zum Teil deutlich von denen in Dubenskijs Veröffentlichungen ab.

Als Zar Nikolaus II. die Putilovwerke in St. Petersburg besuchte, nahm ein heute unbekannter Fotograf zwei Bilder auf, die den Monarchen umgeben von Arbeitern zeigen. Die Leitung der Putilovwerke ließ zahlreiche Abzüge dieser Gruppenfotografien anfertigen und integrierte sie in Alben oder verwendete sie als Einzelaufnahmen. ${ }^{150}$ Eventuell waren diese Fotografien Geschenke für leitende Personen innerhalb des Betriebs oder sie schmückten Räumlichkeiten der Firma und erinnerten an den hohen Besuch.

Die beiden Aufnahmen bilden den Auftakt der großformatigen Erinnerungsalben, welche das Unternehmen 1915 in Auftrag gab. ${ }^{151}$ Für wen genau die 30-seitigen Alben bestimmt waren, lässt sich heute nicht mehr nachvollziehen. Wahrscheinlich für ein firmenexternes Publikum, worauf die aufwendige Gestaltung mit Goldschnitt und Goldprägungen auf dem Umschlag hindeutet. Es gibt keine Hinweise, dass sie Geschenke für das Staatsoberhaupt gewesen wären.

Der Bildaufbau der beiden Gruppenaufnahmen mit Nikolaus II. (Abb. 8o) ist mit dem der Fotografien Jagel'skijs vergleichbar. Beide Aufnahmen zeigen den Zaren relativ zentral umgeben von zahlreichen Arbeitern - seinen ihm anbefohlenen Untertanen. Allerdings kam dem Fotografen in den Putilovwerken nicht die Rolle eines diskreten Beobachters zu. Für den Betrachter ist eindeutig deren inszenierter Charakter zu erkennen, und wie bei klassischen Gruppenaufnahmen blicken die Abgebildeten direkt in die Kamera. Besonders bei Abbildung 80 sind rechts im Vordergrund und links des Zaren viele Arbeiter unscharf, was der Fotografie einen spontanen Charakter verleiht. Nikolaus II. erscheint dagegen gestochen scharf im Zentrum des Bildes. Sein hellgrauer Mantel und das von oben einströmende Licht heben seine Person von der Umgebung ab und unterstreichen seine Bedeutung. Teilweise ließen die Herausgeber die Aufnahmen zuschneiden, so dass der geänderte Bildaufbau

150 Unsystematisch aufbewahrte Abzüge in den fotografischen Beständen des MKZ.

151 Folgende Bibliotheken und Archive haben die entsprechenden Aufnahmen in ihren Beständen: RGB FO: Inz MK XII-1309; GARF f. 826, op. 1, d. 964; CGAKFF A 1861-1877. Problematisch ist, dass im CGAKFF die Fotografien einzelne Signaturen haben und nicht klar ist, welche Bilder in einem Album zusammengefasst sind. Zumindest einen Teil der Fotografien fertigte ein Fotograf der Bildagentur Bulla an. Weil es sich um Fotografien des Zaren handelte, ist anzunehmen, dass Karl Karlovič Bulla selbst oder einer seiner Söhne den Auftrag übernahm. Es ist jedoch nicht sicher, ob die Bildagentur Bulla alle Fotografien anfertigte, aber zumindest ein Teil der Bilder wird ihr zugeschrieben. Siehe: CGAKFF E 3418. 


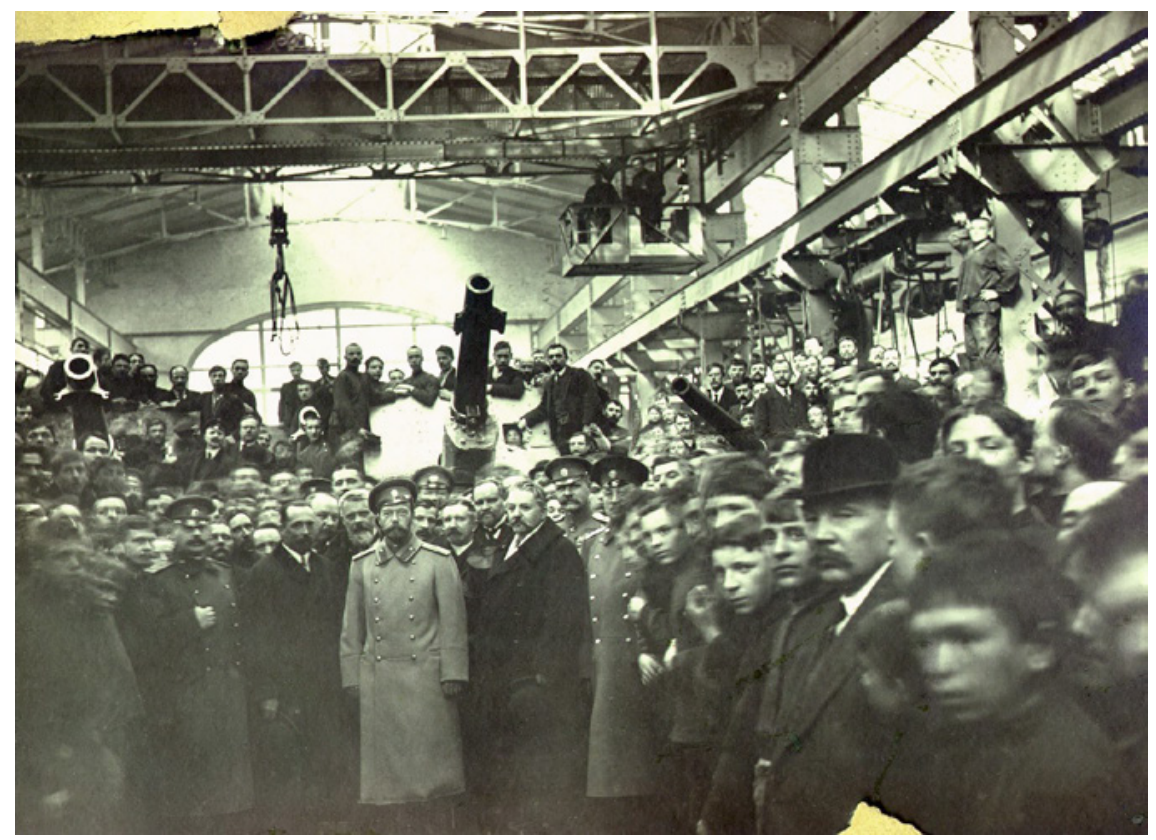

Abb. 80

Obščestvo Putilovskij Zavod (Hrsg.): Zur Erinnerung an den Besuch seiner Kaiserlichen Hoheit in den Putilovwerken und der Werft, am 31. März 1915 (V pamjat' poseščenija ego Imperatorskim veličestvom Putilovskago zavoda i verfi, $3_{1}$ Marta 1915 goda), Petrograd 1915, S. 2. RGB Inz MK XII-1309; GARF f. 826, op. 1, d. 964; MKZ lose Aufnahmen

die zentrale Position des Zaren zusätzlich betonte und dessen Bedeutung visuell untermauerte. ${ }^{152}$ Ein entscheidender Unterschied zu den Aufnahmen in Dubenskijs Publikation ist jedoch die Präsenz des Ersten Weltkriegs in den Fotografien. In Abbildung 8o ragen im Hintergrund Panzer-Geschützrohre aus der Menschenmenge und verweisen unmissverständlich auf den parallel ausgetragenen Konflikt. Entsprechend der Narrative aus Dubenskijs Bänden erstaunt nicht, dass diese Aufnahme in illustrierten Zeitschriften nicht erschien. Der Bruch mit dem Image des Zaren wäre zu groß gewesen.

In den Erinnerungsalben schließen an die beiden Gruppenaufnahmen Fotografien aus den Werkstätten und der Werft an. Es sind besonders diese 28 Aufnahmen, die den Schluss nahelegen, dass die Fabrik nach eigenem Gutdünken ihre Alben zusammenstellte. Der Monarch ist nirgends zu sehen, stattdessen wird die ganze Palette der Waffenproduktion vorgeführt. ${ }^{153}$ Die

\footnotetext{
$15^{2}$ RGB FO: Inz MK XII-1309, S. 31-32.

153 RGB FO: Inz MK XII-1309, S. 5-7, 9-11, 25
} 
Fabrikfotografien entstanden wahrscheinlich zu einem früheren Zeitpunkt, wofür einerseits die bessere Qualität der Abzüge spricht und andererseits das aufwendige Arrangement, das vom Fotografen viel Zeit für die Inszenierung erforderte. ${ }^{154}$ Dreieinhalb Stunden, so lange dauerte der Besuch des Zaren, ${ }^{155}$ dürften dafür kaum ausgereicht haben.

Die Fotografien Nikolaus II. in den Erinnerungsalben der Putilovwerke sollten den Betrachter unmittelbar von der großen Bedeutung des Unternehmens überzeugen. Er begleitete den Monarchen scheinbar auf dessen Rundgang über das Firmengelände. Dieses Prinzip des virtuellen Rundgangs nutzten auch die Herausgeber des Erinnerungsalbums, das der Aleksandrovskij Južno-Rossijskij zavod (Alexandrovsker südrussländischer Betrieb) ${ }^{156}$ dem Zaren schenkte. ${ }^{157}$ Den Bezug zur Visite des Staatsoberhaupts stellt eine Fotografie auf den ersten Seiten des Albums her. Sie zeigt einen Grundriss des Firmenareals mit der eingezeichneten Strecke, der Nikolaus II. bei seiner Besichtigung im Januar 1915 gefolgt war. Im Gegensatz zum Album der Putilovwerke ist in diesem Fall der Adressat klar benannt, es handelt sich um den Monarchen selbst, dessen Portrait in Uniform das Album eröffnet. ${ }^{158}$ Der Zar sollte sich mithilfe der ausführlichen Beschreibung und der 45 Fotografien an seinen Besuch in der Fabrik erinnern. Ausführliche Textpassagen geben detaillierte Informationen über die Firma, ihre Angestellten und die Produktion. Der Vergleich der Fotografien mit der Besichtigungsroute zeigt, dass die Herausgeber sich nicht auf die Teile der Fabrik beschränkten, die der Zar persönlich besucht hatte. Sie zeigten beispielsweise eine Fotografie der Werkstatt zur Fertigung von Brücken, obwohl Nikolaus II. laut Plan nicht dort gewesen war. Der Zar sollte mithilfe der Bilder eine Übersicht über das gesamte Unternehmen erhalten. ${ }^{159}$

154 RGB FO: Inz MK XII-1309, S. 14.

155 31.3.1915, K. F. Facillo (Hrsg.): Dnevnik Imperatora Nikolaja II, Moskva 1991, S. 521.

156 Das Unternehmen wurde 1885 gegründet und war Teil der Aktiengesellschaft der Maschinenfabrik in Brjansk.

157 o. A.: Prebyvanie ego Imperatorskago veličestva.

$15^{8}$ Es handelt sich hierbei um das gleiche Portrait wie im Jubiläumsband, das anlässlich des 300. Thronjubiläums der Romanovs 1913 erschien. Platon Vasenko: Bojare Romanovy i vocarenie Michaila Feodoroviča. Izdanie Komiteta dlja ustrojstva prazdnovanija trechsotletija carstvovanija Doma Romanovych, Sankt-Peterburg 1913. Folglich handelte es sich um ein offizielles Herrscherportrait, das Herausgeber für ihre Publikationen in St. Petersburg bestellen konnten. Siehe hierzu beispielsweise: GATO f. 187, op. 2, d. 133, l. 46.

159 o. A.: Prebyvanie ego Imperatorskago veličestva, S. 8, 71. Wann genau der Zar das Album zum Geschenk erhielt, ist unklar, denn Dubenskij erwähnt zweimal, dass Nikolaus II. ein Album bekommen habe. Dubenskij: Ego Imperatorskoe Veličestvo, Bd. 1, S. 57, 161-162. Bei genauerer Untersuchung fällt auf, dass der Fotograf für die Abbildung des Grundrisses 
Damit unterscheidet sich das Album entscheidend von den in diesem Teilkapitel bislang analysierten Publikationen, denn der Blick der Herausgeber richtete sich nicht auf ein öffentliches Publikum, sondern auf das Staatsoberhaupt selbst. Diese Quelle gibt folglich keine Antworten auf die Frage, wie sich der Zar in Zusammenhang mit der Schwerindustrie inszenierte. Vielmehr gibt sie Hinweise darauf, welche Bildmotive den Industriellen für Nikolaus II. angemessen erschienen.

Es fällt auf, dass die Inhaber des Stahlwerks selbstbewusst die Hochöfen und den Verarbeitungsprozess präsentierten.160 Dies war nicht selbstverständlich. In der Vorkriegszeit galten Fotografien, die die Naturgewalten bei der Roheisen- und Stahlherstellung festhielten, als zu einschüchternd für das russische Publikum. Betriebe griffen für ihre Selbstpräsentationen kaum auf entsprechende Aufnahmen zurück. ${ }^{161}$ Zudem war es für Lichtbildner eine besondere Herausforderung, Aufnahmen von der Stahlherstellung und Metallverarbeitung anzufertigen, weil extreme Hell-Dunkel-Kontraste, große Hitze und Funkenflug die Arbeit erschwerten und eine Gefahr für die technische Ausstattung darstellten. ${ }^{162}$ Umso mehr demonstriert die Qualität der hier aufgenommenen Fotografien das große Können des Fotografen. Aufnahmen von Hochöfen mit Dampf- oder Rauchwolken (Abb. 81) sowie von glühendem Metall (Abb. 82) unterstreichen dies eindrücklich.

Die Dynamik der Hochofenfotografie (Abb. 81) entsteht durch den Größenvergleich zu den angrenzenden Gebäuden. Entscheidender ist jedoch die

sowie die Aufnahme des Bahnsteigs und der Belegschaft, die auf den Zaren wartete, glattes Fotopapier verwendete. Für die anderen Abzüge nutzte er ein Papier mit einer deutlich sichtbaren groben Struktur (Abb. 25 und Abb. 81). Dies und die Beobachtung, dass auch Teile des Unternehmens präsentiert wurden, die der Zar nicht gesehen hatte, legt nahe, dass der überwiegende Teil der Fotografien und Texte vorbereitet waren und der Fotograf am 31. Januar 1915 nur noch zwei Aufnahmen machte, entwickelte und an die ausgesparten Stellen klebte. Vermutlich erhielt Nikolaus II. das Album unmittelbar vor seiner Abreise aus Ekaterinoslav.

16o Auch im Album des Putilovskij zavod findet sich eine Fotografie, die glühendes Metall zeigt. RGB FO: Inz MK XII-1309, S. 27.

161 Dies galt einerseits für die Fotografien in illustrierten Zeitschriften (siehe: Kapitel „Fabriken als Konsumartikel - Illustrierte Zeitschriften“, S. 241-282). Aber auch in Fotoalben waren in der Vorkriegszeit vergleichbare Aufnahmen selten zu finden. MKZ Nr. 2: o. A.: Obščestvo Putilovskich Zavodov, o. O. vor 1907.

162 Aus diesem Grund entschieden sich Fotografen teilweise dazu, kalte Eisenstücke mit weißer Farbe anzustreichen, so dass diese auf den Schwarz-Weiß-Aufnahmen auf den ersten Blick als hell glühend erschienen. Fehlende Lichtreflektionen und fehlender Wasserdampf zeigen dem aufmerksamen Beobachter jedoch, bei welchen Aufnahmen der Fotograf künstlich nachgeholfen hat. Wengenroth: Die Fotografie als Quelle der Arbeits- und Technikgeschichte, S. 96-97. 


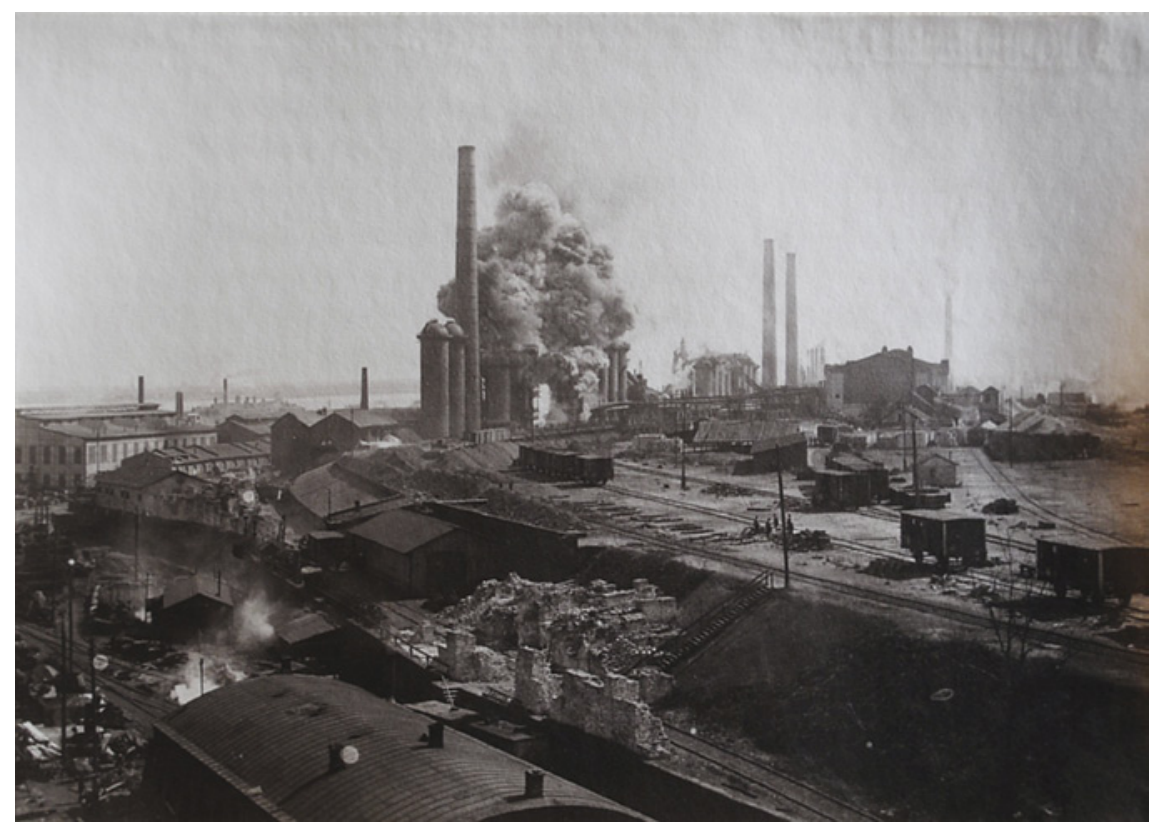

Abb. 81

o. A.: o. T., in: Seiner Kaiserlichen Hoheit dem Monarchen und Zaren Nikolaj Aleksandrovič. Alleruntertänigst von der Aktiengesellschaft des Brjansker Schienenwalzwerks, eisenschaffenden und mechanischen Betriebs. Besuch seiner Kaiserlichen Hoheit Monarch und Zar im Aleksandrovsker Južno-Rossijsker Betrieb der Brjansker Gesellschaft in Ekaterinoslav, am 31. Januar 1915 (Ego Imperatorskomu Veličestvu gosudarju Imperatoru Nikolaju Aleksandroviču. Vsepodannejše ot akcionernago o-va Brjanskago rel'soproklatnago, železodelatel'nago i mechaničeskago zavoda. Prebyvanie ego Imperatorskago Veličestva, gosudarja Imperatora na Aleksandrovkom južno-rossijskom zavod Brjanskago obščestva v Ekaterinoslave, 31 janvarja 1915 goda), Moskva 1915, S. 23. NGBË ORK RK 278762

große Dampfwolke, die zwischen den Schornsteinen und Kesseln aufsteigt. Obwohl nur im Hintergrund abgebildet, zieht dieses Bilddetail die Aufmerksamkeit des Betrachters auf sich und gibt ihm eine Ahnung des beeindruckenden Schauspiels. Dagegen erscheint die Aufnahme von der Verarbeitung der Eisendrähte nüchtern und unaufgeregt. Nur vor dem rechten Drahtbündel sind helle Schlieren zu sehen, die den Funkenflug dokumentieren. Während in früheren Alben besonders die Ästhetik der Maschinen und Architektur inszeniert wurde und die Fabriken als geordnete Räume erschienen, zeigt sich hier (besonders in Abb. 82) ein anderer Aspekt - die Kraft der Naturelemente, die an der industriellen Produktion beteiligt sind. Zwar scheinen sie durch die Technik und den Menschen gebändigt, doch der Betrachter kann unschwer erkennen, dass im Falle eines Unglücks ein großes Zerstörungspotential vorhanden wäre. 


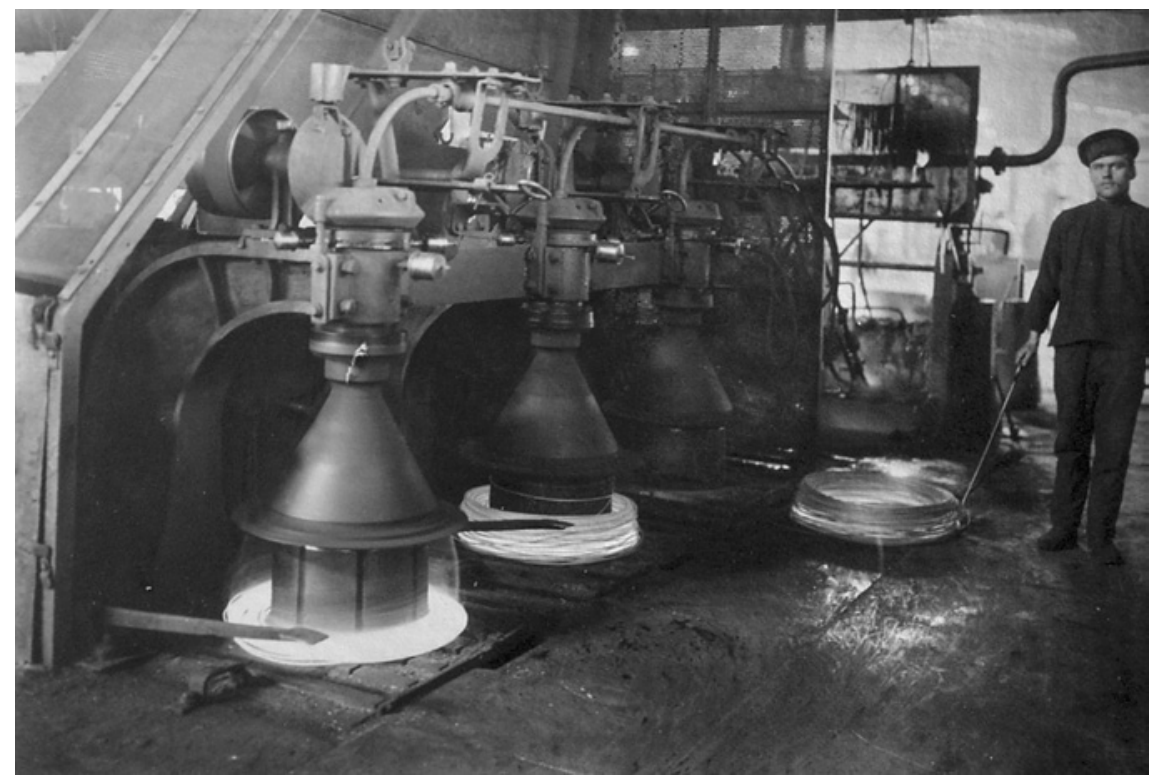

Abb. 82 o. A., o. T., in: Seiner Kaiserlichen Hoheit dem Monarchen und Zaren Nikolaj Aleksandrovič. Alleruntertänigst von der Aktiengesellschaft des Brjansker Schienenwalzwerks, eisenschaffenden und mechanischen Betriebs. Besuch seiner Kaiserlichen Hoheit Monarch und Zar im Aleksandrovsker Južno-Rossijsker Betrieb der Brjansker Gesellschaft in Ekaterinoslav, am 31. Januar 1915 (Ego Imperatorskomu Veličestvu gosudarju Imperatoru Nikolaju Aleksandroviču. Vsepodannejše ot akcionernago o-va Brjanskago rel'soproklatnago, železodelatel'nago i mechaničeskago zavoda. Prebyvanie ego Imperatorskago Veličestva, gosudarja Imperatora na Aleksandrovkom južno-rossijskom zavod Brjanskago obščestva v Ekaterinoslave, 31 janvarja 1915 goda), Moskva 1915, S. 55. NGBÉ ORK RK 278762

Mit diesen Motiven trafen die Herausgeber den Geschmack des Zaren. Nur selten lässt sich so klar nachvollziehen, welchen Eindruck Fabrikbesuche bei den Zeitgenossen hinterließen. Das russische Staatsoberhaupt hielt in kurzen Notizen seinen Tagesablauf fest und erwähnte dabei auch die Fabrikbesichtigungen. In seinem Tagebucheintrag vom 31. Januar 1915 betonte Nikolaus II., wie ihn die Herstellung von Eisenbahnschienen und das Schauspiel der Hochöfen im Aleksandrovskij Južno-Rossijskij zavod fasziniert hatten. ${ }^{163}$ Eine solch positive Schilderung der Industrie und Technik ist eine

163 31.1.1915, Facillo (Hrsg.): Dnevnik Imperatora Nikolaja II, S. 512. Generell sind die Schilderungen der Fabrikbesuche, die Nikolaus II. in sein Tagebuch notierte, sehr kurz. Noch weniger Informationen über seine Eindrücke enthalten die Telegramme, die er an die Zarin schickte. Beispielsweise: Jospeh T. Fuhrmann (Hrsg.): The Complete Wartime 
Seltenheit in den Aufzeichnungen des Monarchen. In den Vorkriegsjahren erwähnte Nikolaus II. höchstens seinen Besuch, ging aber nicht näher auf die Besichtigungen ein. Somit lässt sich hier eine Veränderung in der Haltung des Monarchen gegenüber der Industrie, insbesondere der Schwerindustrie konstatieren. ${ }^{164}$ Die Besuche des Zaren in den Rüstungsbetrieben waren zwar Teil eines propagandistischen Feldzugs, doch das Staatsoberhaupt entdeckte im Zuge der Reisen auch seine Begeisterung und seinen Stolz über die Leistungen der russischen Fabriken. ${ }^{165}$

\subsection{Fazit}

Während Fabriken in der Vorkriegszeit in den Bildwelten des Zarenreichs eher eine Nebenrolle spielten, entwickelten sie sich mit Beginn des Ersten Weltkriegs zu einem patriotischen Vorzeigemotiv. Sogar der Zar, der bisher einen großen Bogen um die Industrie gemacht und Industriellen wie Fabrikarbeitern eher ablehnend gegenüber gestanden hatte, ließ sich nun während seiner Besuche in Rüstungs- und metallverarbeitenden Betrieben fotografieren. Das Verhältnis der russischen Gesellschaft gegenüber der Industrie wandelte sich, und es waren nicht mehr die Unternehmer selbst, die dafür Sorge trugen, dass Fabriken in der Berichterstattung Beachtung fanden. Gerade vor dem Hintergrund des verlorenen Krimkriegs und der Niederlage im Russisch-Japanischen Krieg war es für die russische Propaganda unerlässlich, die militärische Stärke des Reichs visuell heraufzubeschwören.

Hierzu erschienen in den russischen Illustrierten Fotografien von Waffen, die die Abgebildeten mit fast zärtlichen Posen präsentierten oder die den schier unendlichen Nachschub in den Arsenalen der Alliierten inszenierten. Allgemein lässt sich in den hier analysierten Aufnahmen ein Hang zu Motiven feststellen, die stärker als in der Vorkriegszeit auf monumentale Elemente bauten. Jetzt durfte die Industrie die hier herrschenden Kräfte zeigen, ohne

Correspondence of Tsar Nicholas II. and the Empress Alexandra. April 1914-March 1917, Westport, Connecticut, London 1999, S. 47-48, 119, $125,227$.

164 In seinem Tagebuch erwähnt der Zar regelmäßig Besuche in Porzellanmanufakturen und beim Baltijskij zavod. Allerdings handelte es sich bei den Besuchen des Baltijski zavod meist um den Stapellauf wichtiger Schiffe und nicht um eine Besichtigung der Werkshallen und Produktionsanlagen.

165 Nikolaus II. betonte, dass im Aleksandrovskij Južno-Rossijskij zavod ausschließlich russische Arbeiter tätig waren. 31. Januar 1915, Facillo (Hrsg.): Dnevnik Imperatora Nikolaja II, S. 512 . 
dass sie angsteinflößend gewesen wären. Vor dem Hintergrund des Kriegs richtete sich ihre Zerstörungskraft in erster Linie gegen den Feind.

Die revolutionären Ereignisse 1905 hatten gezeigt, dass auch Unruhen im Inneren des Landes die Position des Russischen Reichs erheblich schwächen konnten. Aus diesem Grund bemühte sich Zar Nikolaus II., den Arbeitern zu vermitteln, dass er sich als sorgender Landesvater um sie kümmerte und sich für ihre Belange einsetzte. Er erweiterte damit die Definition des russischen Volkes, wie er sie bisher in seiner Selbstinszenierung gebraucht hatte, und neben die Gruppe der Bauern stiegen nun auch die Arbeiter in den Status der schutzbefohlenen Untertanen auf. Allerdings autorisierte der Zar Aufnahmen von sich in Fabriken nur dann, wenn diese im geschützten Kontext von Dubenskijs Publikation erschienen. Vermutlich fürchtete er, dass die Aufnahmen in Zeitschriften und ohne den abgesegneten Begleittext für ihm nicht genehme Narrative gebraucht werden könnten. Das Beispiel des Albums der Putilovwerke zeigt, dass diese Bedenken begründet waren.

Je länger der Krieg dauerte und je stärker er sich zu einer Materialschlacht entwickelte, desto wichtiger wurden die Rüstungsbetriebe. Der Zar adelte die Fabriken, indem er die Aufnahmen seiner Visiten veröffentlichen ließ, und machte Industriefotografien damit salonfähig. Um angesichts des Mangels an fotografischen Aufnahmen die Nachfrage zu befriedigen, griffen Herausgeber russischer Illustrierter auf englische und französische Fotografien zurück, die immer öfter auch Arbeiterinnen in der Industrie zeigten. Neben diesem neuen Motiv entwickelten die Fotografen eine neue Bildsprache, bei der sie einzelne Arbeiter und deren Tätigkeit besonders herausstellten. Vor dem Hintergrund des Konflikts erschienen Arbeiter und besonders Arbeiterinnen erstmals in einer ähnlichen Inszenierung, wie sie nach der Oktoberrevolution 1917 in der frühen Sowjetunion üblich werde sollte. Die neue Popularität von Fabriken und die Heldengestalten der Arbeiter gaben einen Vorgeschmack auf die 1920er und 1930er Jahre, in denen Industrie und Arbeiterschaft mit heroisierenden Darstellungen zu einem Kernthema der frühsowjetischen Berichterstattung avancierten, das Portrait einen besonderenStellenwert erhielt ${ }^{166}$ und die Kamera immer näher an die Arbeiter heranrückte. ${ }^{167}$

166 Hierzu beispielsweise: Emily Joyce Evans: Hinwendung und Abkehr vom Arbeiterporträt. Brüche und Kontinuitäten in der Entwicklung des „sowjetischen“ Porträts, 1926-1937, in: Fotogeschichte. Beiträge zur Geschichte und Ästhetik der Fotografie, Jg. 35/2015, Heft 136, S. $33-42$.

167 Abbildungen in: J. Ribalta; E. Witschey (Hrsg.): The Worker Photography Movement [1926-1939]. Essays and Documents, Madrid 2011, S. 26-29; Stigneev: Vek fotografii, S. 344, 350. 